\title{
EFEITO DE EXTRATOS AQUOSOS DE Trichilia spp. SOBRE O DESENVOLVIMENTO DE Spodoptera frugiperda (J.E. Smith) EM MILHO
}

Paulo Cesar Bogorni

Engenheiro Agrônomo

Orientador: Prof. Dr. JOSÉ DJAIR VENDRAMIM

Tese apresentada à Escola Superior de Agricultura "Luiz de Queiroz", Universidade de São Paulo, para obtenção do título de Doutor em Ciências, Área de Concentração: Entomologia.

PIRACICABA

Estado de São Paulo - Brasil Janeiro - 2003 


\section{Dados I nternaci onai s de Catal ogação na Publ ì cação ( CI P) DI VI SÃO DE BI BLI OTECA E DOCUNENTAÇÃO - ESALQ/USP}

\section{Bogorni, Paulo Cesar}

Efeito de extratos aquosos de Trichilia spp. sobre o desenvolvimento de Spodoptera frugiperda (J.E. Smith) / Paulo Cesar Bogorni. - - Piracicaba, 2003.

65 p. : il.

Tese (doutorado) - Escola Superior de Agricultura Luiz de Queiroz, 2003.

Bibliografia.

1. Controle biológico (Fitossanidade) 2. Controle de pragas 3. Lagartas 4. Milho 5. Pesticidas 6. Plantas produtoras de pesticidas I. Título 
À minha esposa, Ana Paula,

Dedico 


\section{AGRADECIMENTOS}

Ao Prof. Dr. José Djair Vendramim, pela orientação, amizade, compreensão e oportunidade de realizar o Curso de Pós-graduação nesta Escola.

Ao Concelho Nacional de Desenvolvimento Científico e Tecnológico ( $\mathrm{CNPq}$ ), pela concessão da bolsa de estudos.

Aos Professores do Programa de Pós-graduação em Entomologia da ESALQ/USP, pelos ensinamentos.

Aos Professores Ana Odete Santos Vieira e José Marcelo Torezan, do Departamento de Biologia Animal e Vegetal da Universidade Estadual de Londrina, pelo auxilio na coleta e identificação do material vegetal utilizado neste trabalho.

Ao Professor Rogério Fernando Pires da Silva, pela amizade, apoio e confiança.

Aos amigos e colegas Ricardo A. Polanczyk, Márcio A. Tavares, Luciane K. Junqueira e Uemerson S. da Cunha, pelas sugestões, apoio e companheirismo.

Aos colegas da área de resistência de plantas e plantas inseticidas, Fábio, Maria Auxiliadora, Rogério, Romildo e Antonio, pelo apoio e companheirismo.

A todos os colegas de Pós-graduação e, em especial, a Fábio B. Schmidt, Marilene Fancelli, Enrique Castiglioni, Rita Gonçalves-Gervásio, Luciano Ribeiro, Marcos B. de Medeiros, pela amizade e companheirismo. 
A Vanessa C. Pansiera, pelo inestimável auxilio durante toda a realização do trabalho.

Aos funcionários do Setor de Entomologia da ESALQ/USP, pelos auxilios prestados.

$E$ a todos aqueles que, direta ou indiretamente, contribuíram para a realização deste trabalho. 


\section{SUMÁRIO}

Página

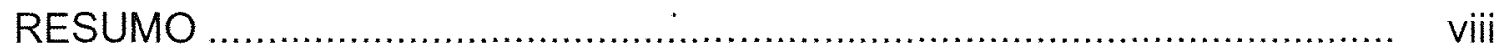

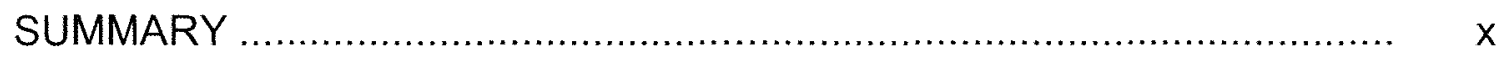

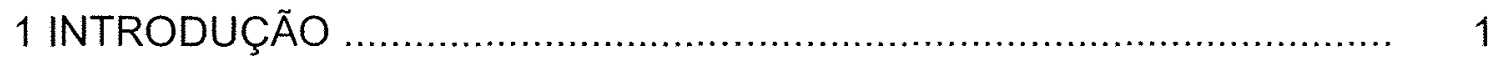

2 REVISÃO DE LITERATURA ..................................................... 3

2.1 Considerações gerais sobre a bioecologia de Spodoptera frugiperda (J.E. Smith) ........................................................................ 3

2.2 Inseticidas botânicos ................................................................. 5

2.2.1 Nim e as meliáceas ............................................................ 5

2.2.2 Efeito de Trichilia spp. sobre S. frugiperda ................................ 7

2.2.3 Efeito de Trichilia spp. sobre outros insetos.................................. 9

2.2.4 Efeito de outras meliáceas sobre $S$. frugiperda ........................... 13

3 MATERIAL E MÉTODOS.............................................................. 16

3.1 Criação dos insetos ................................................................. 16

3.2 Obtenção e preparo do material vegetal .......................................... 17

3.2.1 Coleta e acondicionamento das partes vegetais .......................... 17

3.2.2 Preparação dos extratos ......................................................... 20

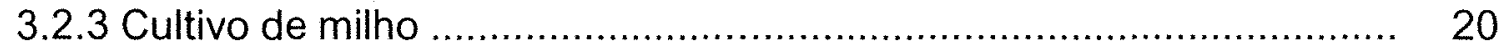

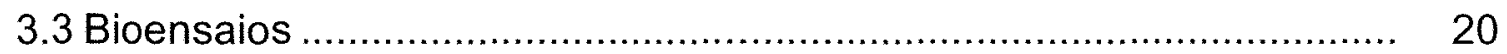

3.3.1 Bioensaios de laboratório ......................................................... 21

3.3.1.1 Efeito dos extratos de seis espécies de Trichilia e de Azadirachta indica na sobrevivência e peso larval ao $5^{\circ}$ dia de S. frugiperda ... 
3.3.1.2 Efeito dos extratos de seis espécies de Trichilia sobre o desenvolvimento do inseto.

3.3.1.3 Preferência de lagartas por folhas de milho tratadas e não tratadas com extratos de Trichilia spp.

23

3.3.2 Bioensaio de campo 25

3.4 Análise estatística 27

4 RESULTADOS E DISCUSSÃO 28

4.1 Bioensaios de laboratório 28

4.1.1 Efeito dos extratos de meliáceas na sobrevivência e peso larval ao $5^{\circ}$ dia de Spodoptera frugiperda (J.E. Smith)

4.1.1.1 Efeito de extratos de folhas e ramos de seis espécies de Trichilia e de sementes de Azadirachta indica

4.1.1.2 Efeito de extratos de folhas e ramos de $T$. pallida e $T$. pallens ...... 31

4.1.1.3 Efeito de extratos de diversas estruturas vegetais de T. pallens ... 33

4.1.2 Efeito dos extratos de seis espécies de Trichilia sobre o desenvolvimento do inseto

4.1.2.1 Fase larval ............................................................................ 35

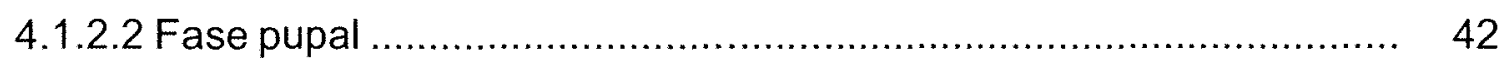

4.1.2.3 Adultos defeituosos .............................................................. 44

4.1.3 Preferência de lagartas por folhas de milho tratadas e não tratadas com extratos de Trichilia spp. ....................................................... 47

4.2 Bioensaio de campo ............................................................. 48

5 CONCLUSÕES ................................................................. 51

REFERÊNCIAS BIBLIOGRÁFICAS .......................................... 53 


\title{
EFEITO DE EXTRATOS AQUOSOS DE Trichilia spp. SOBRE O DESENVOLVIMENTO DE Spodoptera frugiperda (J.E. Smith) EM MILHO
}

\author{
Autor: PAULO CESAR BOGORNI \\ Orientador: Prof. Dr. JOSÉ DJAIR VENDRAMIM
}

\section{RESUMO}

O uso de plantas inseticidas vem ressurgindo como uma promissora ferramenta de controle de pragas, visando reduzir a dependência dos produtos sintéticos, prejudiciais ao homem e ao ambiente. Nesse trabalho, foi avaliada a eficiência de extratos aquosos de seis espécies de Trichilia ( $T$. casaretti, $T$. catigua, $T$. claussenii, $T$. elegans, $T$. pallens e $T$. pallida), em comparação com o extrato aquoso de sementes de Azadirachta indica (nim) sobre Spodoptera frugiperda em condições de laboratório e de campo. Inicialmente, foi avaliado o efeito dos extratos, a $5 \%$ (peso/volume), de ramos e folhas das seis espécies na sobrevivência e peso larval ao quinto dia e, a seguir, foi determinado o efeito dos mesmos extratos, a $1 \%$, na sobrevivência, duração e peso das fases larval e pupal. Foi avaliado ainda o efeito dos referidos extratos sobre o consumo alimentar de lagartas de quarto instar. Com base nesses testes, foram selecionados os extratos mais eficientes (ramos e folhas de T. pallens e de ramos de T. pallida) para avaliação da eficiência em condições de campo em comparação com o inseticida lufenuron (Match ${ }^{\circledast} \mathrm{CE}$ ), o óleo de nim e o extrato aquoso de sementes de nim. Os resultados obtidos permitiram concluir que para 
as seis espécies de Trichilia testadas, ao menos uma das suas estruturas (ramos ou folhas) afeta o desenvolvimento de S. frugiperda. À concentração de $5 \%$, constatou-se que: o extrato de folhas de $T$. pallens causa $100 \%$ de mortalidade larval até $05^{\circ}$ dia, efeito semelhante ao causado pelo extrato de nim; os extratos de ramos e frutos (verdes e maduros) de T. pallens, e de ramos e folhas de T. pallida, embora menos eficientes que os extratos de folhas de $T$. pallens e de sementes de nim, também reduzem a sobrevivência e o peso larval dessa praga. À concentração de 1\%, verificou-se que os extratos de ramos de $T$. pallida e de folhas de $T$. pallens são os mais eficientes, dentre as seis espécies de Trichilia testadas, embora os extratos de folhas de T. pallida, $T$. catigua, $T$. casaretti e $T$. elegans e os extratos de ramos de $T$. claussenii e $T$. pallens também afetem o desenvolvimento do inseto; os extratos de folhas de $T$. catigua e $T$. claussenii, e de ramos de $T$. catigua inibem a alimentação de lagartas, enquanto que o extrato de ramos de $T$. elegans é fago-estimulante. Em condições de campo, os extratos de folhas de T. pallens e de sementes de A. indica, a $6,7 \%$, embora menos eficientes que o inseticida sintético lufenuron, reduzem o dano das lagartas à cultura do milho. 


\title{
EFFECT OF Trichilia spp. AQUEOUS EXTRACTS ON Spodoptera frugiperda (J. E. Smith) DEVELOPMENT ON CORN
}

\author{
Author: PAULO CESAR BOGORNI \\ Adviser: Prof. Dr. JOSÉ DJAIR VENDRAMIM
}

\section{SUMMARY}

The use of insecticidal plants has increased its importance in pest control, aiming to reduce the chemicals dependence, that prejudice the man and environmental. In this research, the efficacy of aqueous extracts from six Trichilia species ( $T$. casaretti, $T$. catigua, $T$. claussenii, $T$. elegans, $T$. pallens and T. pallida) on S. frugiperda was evaluated at laboratory and field conditions, comparing it with the aqueous extract from Azadirachta indica (neem) seeds. Initially, it was evaluated the extract effects at $5 \%$ (weight/volume) of twigs and leaves from the six species on survival and larval weight at the fifth day after treatment. And, after that, the effect of the same extracts at $1 \%$ on survival, duration and weight of pupal and larval stages was determined. Also the extract effect on food consumption of fourth instar larvae was evaluated. Based on these assays, the most efficient extracts (twigs and leaves of $T$. pallens and $T$. pallida) were selected to have their efficiency evaluated in field conditions comparing with the chemical lufenuron (Match ${ }^{\circledR} \mathrm{CE}$ ), neem oil and aqueous extract of neem seeds. The results allowed to conclude that in the six Trichilia species tested, at least one of their structures (twigs or leaves) affects the $S$. 
frugiperda development. At $5 \%$ the extract from leaves of T. pallens cause larval mortality of $100 \%$ until five days after treatment, similar effect showed by neem extract; the extracts from twigs and fruits (unripe and ripe) of $T$. pallens, and twigs and leaves of $T$. pallida, although less efficient than the extracts from leaves of $T$. pallens and neem seeds, also reduce the larval weight and survival. At $1 \%$ the extracts from twigs of $T$. pallida and leaves of $T$. pallens are the most efficient, among the six Trichilia spp., although the extracts from leaves of $T$. pallida, $T$. catigua, $T$. casaretti and $T$. elegans and the extracts from twigs of $T$. claussenii and $T$. pallens also affect the insect development; the extracts from leaves of $T$. catigua and $T$. claussenii, and twigs of $T$. catigua inhibit the food consumption, while the twigs of $T$. elegans stimulate it. In field conditions, the extracts from leaves of $T$. pallens and $A$. indica seeds, at $6,7 \%$, although less efficient that the chemical lufenuron, also reduce the damage caused by larvae in the corn. 


\section{INTRODUÇÃO}

A lagarta-do-cartucho do milho, Spodoptera frugiperda (J.E. Smith), é uma das principais pragas da cultura do milho, em praticamente todas as regiões produtoras no país, tanto pelo seu potencial de causar dano, como pela dificuldade no seu controle.

Os danos causados por este inseto à cultura do milho podem levar à redução de até $34 \%$ no rendimento de grãos, dependendo, principalmente, do estádio da cultura em que ocorre o ataque (Carvalho, 1970; Cruz, 1995; Valicente \& Cruz, 1991). Dentre outros fatores abióticos, a precipitação pluvial pode influenciar a intensidade de ataque; chuvas menos intensas seguidas de períodos secos e quentes podem provocar grande aumento populacional da praga, reduzindo em até $60 \%$ o peso médio das espigas (Bianco, 1991).

A dificuldade no controle deste noctuídeo, juntamente com a utilização incorreta de inseticidas, vêm ocasionando aumento no número de aplicações (Cruz, 1995). Tal situação agrava o problema de contaminação dos produtos agrícolas, agricultores e do meio ambiente (Crocomo \& Parra, 1985). Desta forma, a utilização de medidas de controle que causem menor impacto ambiental é de primordial importância.

Neste sentido, as plantas inseticidas vêm ressurgindo como uma promissora ferramenta para controle de insetos-praga (Klocke, 1987). Tais plantas podem ser utilizadas tanto diretamente no controle de insetos, através da aplicação de pós, óleos ou extratos brutos obtidos a partir de suas estruturas vegetais, quanto pela identificação de compostos com ação inseticida, 
permitindo sua utilização em larga escala, através da extração ou síntese industrial de tais compostos.

As pesquisas envolvendo plantas inseticidas evoluíram muito nas últimas décadas, em todos os continentes, sendo que, uma das espécies que tem se destacado e que impulsionou essa linha de pesquisa é a meliácea, Azadirachta indica, comumente conhecida por nim. Atualmente, esta espécie é a mais estudada, tendo seu efeito comprovado sobre uma série de insetospraga, inclusive $S$. frugiperda. O interesse por esta espécie deve-se à presença de um limonóide denominado azadiractina, cuja atividade sobre alguns insetos é comparável à dos melhores inseticidas sintéticos encontrados no mercado (Klocke, 1987; Martinez, 2002; Schmutterer, 1990).

Os bons resultados verificados com o nim e a azadiractina têm estimulado pesquisas com outras plantas da família Meliaceae, no intuito de encontrar novas espécies com atividade inseticida, bem como, novos compostos. Neste sentido, o gênero Trichilia vem ganhando destaque, não apenas pela descoberta de limonóides denominados triquilinas (Nakatani et al., 1981), mas também, por ser um dos mais numerosos do grupo (aproximadamente 70 espécies) e ter ampla distribuição pelas regiões tropicais das Américas, o que privilegia o Brasil, pois a grande maioria é encontrada no território nacional, principalmente na região amazônica (Pennigton, 1981).

Nesse sentido, desenvolveu-se este trabalho, com o intuito de avaliar em condições de laboratório e campo, o efeito de extratos aquosos de seis espécies de Trichilia sobre o desenvolvimento de $S$. frugiperda. 


\section{REVISÃO DE LITERATURA}

2.1 Considerações gerais sobre a bioecologia de Spodoptera frugiperda (J.E. Smith)

A lagarta-do-cartucho do milho é um inseto de metamorfose completa, apresentando as fases de ovo, lagarta, pupa e adulto. Os adultos são mariposas que se acasalam no terceiro dia após a emergência, sendo que, em seguida, durante a noite, a fêmea inicia a postura nas folhas, colocando ao redor de 1000 ovos (Brett \& Bastida, 1963; Ferraz, 1982; Leiderman \& Sauer, 1953; Valicente \& Cruz, 1991), podendo chegar em alguns casos a mais de 2000 (Vendramim \& Fancelli, 1988). Os ovos, postos em camadas, são recobertos por filamentos brancos, escamas e pêlos, depositados pelas fêmeas (Ferraz, 1982; Leiderman \& Sauer, 1953).

Embora sejam feitas grandes posturas (140 a 250 ovos por postura), em uma única planta, as lagartas podem migrar para plantas vizinhas à procura de plantas menos atacadas ou tecidos mais macios (Brett \& Bastida, 1963; Cruz, 1995). Normalmente, devido principalmente ao canibalismo que se manifesta a partir do terceiro ínstar, não se encontram mais de duas lagartas por cartucho de milho (Ávila et al., 1997; Bianco, 1991; Cruz, 1995; Gassen, 1994; Leiderman \& Sauer, 1953).

Como na maioria dos insetos, a duração das fases de desenvolvimento é acelerada pelo aumento da temperatura (Ali et al., 1990; Ferraz, 1982). 
O período de incubação é de 2 a 3 dias (Ferraz, 1982; Kasten Jr. et al., 1978; Vendramim \& Fancelli, 1988).

As lagartas de primeiro ínstar atacam inicialmente o parênquima foliar de uma das faces da folha, deixando apenas a epiderme, o que dá um aspecto transparente à folha, conhecido como "folha raspada", muito característico do ataque de lagartas jovens desta espécie (Ávila et al., 1997; Valicente \& Cruz, 1991). Em ínstares mais adiantados, passam a perfurar as folhas, descendo para a região do cartucho onde causam danos mais severos, podendo destruí-lo completamente (Ávila et al., 1997; Cruz, 1995). Quando o ataque se dá nos estádios iniciais da cultura, pode ocorrer a morte de plantas, reduzindo o stand (Waquil et al., 1982). Embora possam ocorrer danos no colmo e na espiga, uma vez que o inseto ataca plantas em todos os estádios de desenvolvimento (Bianco, 1991; Carvalho, 1982; Cruz, 1995), as maiores reduções no rendimento de grãos na cultura ocorrem quando as plantas atacadas apresentam de 8 a 10 folhas (Cruz \& Turpin, 1982).

A fase larval dura de 12,3 a 19,7 dias (Ferraz, 1982; Kasten Jr. et al., 1978; Leiderman \& Sauer, 1953; Melo \& Silva, 1987; Silveira et al., 1997; Vendramim \& Fancelli, 1988), sendo que, à temperatura de $20^{\circ} \mathrm{C}$, Ferraz (1982) constatou a ocorrência de 33,38 dias. No campo $\left(25\right.$ a $\left.27^{\circ} \mathrm{C}\right)$, a duração da fase larval oscila entre 15 e 20 dias (Valicente \& Cruz, 1991).

Durante a fase larval o inseto apresenta de seis a sete instares (Ferraz, 1982; Leiderman \& Sauer, 1953), sendo o maior número observado às menores temperaturas $\left(20^{\circ} \mathrm{C}\right)$ e os maiores danos, ocorrendo no último ínstar, independente da temperatura (Ferraz, 1982).

Em condições de campo, a fase de pupa dura em média 11 dias (Valicente \& Cruz, 1991). Observações em laboratório $\left(25^{\circ} \mathrm{C}\right)$ mostram que a duração da fase oscila entre 8 e 11 dias, sendo o peso pupal variável entre 159 e 250mg (Kasten Jr. et al., 1978; Leiderman \& Sauer, 1953; Melo \& Silva, 1987; Silveira et al., 1997; Vendramim \& Fancelli, 1988). 
Os adultos emergem à noite sendo que o periodo de préoviposição e a longevidade estão ao redor de 4 e 13 dias respectivamente (Cruz, 1995; Ferraz, 1982). Embora o período de oviposição possa ser longo, mais de $50 \%$ dos ovos são postos nos primeiros 4 dias (Ferraz, 1982).

\subsection{Inseticidas botânicos}

\subsubsection{Nim e as meliáceas}

Azadirachta indica A. Juss (Meliaceae), também referida como Antelaea azadirachta, Melia azadirachta e Melia indica, e conhecida popularmente como nim ou margosa, é originária das regiões áridas da Índia (Butterworth \& Morgan, 1971; Koul et al., 1990; Schmutterer, 1990).

Há milênios os hindus já utilizavam derivados desta planta na cura de doenças, como, por exemplo, o suco das folhas para controle de helmintos (Govindachari, 1992). A. indica também era utilizada por agricultores para repelir insetos de grãos armazenados através da mistura de folhas secas da planta aos mesmos (Koul et al., 1990; Schmutterer, 1990).

Durante muitos anos o nim foi utilizado empiricamente e apenas em 1968, segundo Butterworth \& Morgan $\left(1968^{1}\right)$, citados por Butterworth \& Morgan (1971), foi isolado o composto - um limonóide - responsável pela ação sobre insetos. Este composto, denominado azadiractina, só teve sua estrutura elucidada em 1985 e seus efeitos descritos por Schmutterer (1988).

O nim é um dos maiores responsáveis pelo grande interesse atual na busca de novas plantas e de novos compostos inseticidas. Isto se deve ao fato de a azadiractina apresentar atividade comparável a de alguns inseticidas

\footnotetext{
'BUTTERWORTH, J.H.; MORGAN, E.D. Isolation of a substance that suppresses feeding in locusts. Journal of Chemical Society. Chemical communication. p.23-24. 1968.
} 
sintéticos e ação específica em processos bioquímicos e de desenvolvimento muito peculiares dos insetos (Klocke, 1987).

A azadiractina não é o único composto com atividade inseticida encontrado no nim. Existem descritos outros 14 limonóides, além da azadiractina, presentes em diversas partes da planta, mas em maior concentração nas sementes (Govindachari, 1992; Govindachari \& Gopalakrishnan, 1997; Koul et al., 1990).

O número de espécies de pragas para as quais o nim apresenta atividade inseticida foi citado como sendo 128 segundo Bambarkar (1990) e mais de 200 espécies segundo Govindachari (1992), estimando-se atualmente que o seu efeito já tenha sido determinado sobre mais de 400 espécies de insetos (Martinez, 2002). Os efeitos do nim são variados incluindo-se: mortalidade de adultos e formas jovens, deterrência alimentar, inibição do crescimento, alteração no comportamento de oviposição e alimentação, redução da fecundidade, esterilização, alterações da metamorfose, redução do vigor e repelência (Martinez, 2002; Mordue (Luntz) \& Blackwell, 1993; Schmutterer, 1988, 1990; Warthen Jr., 1989). Os efeitos do nim sobre os insetos, inclusive sobre $S$. frugiperda, já foram amplamente discutidos e podem ser encontrados em diversas revisões de literatura (Govindachari, 1992; Koul et al., 1990; Mordue (Luntz) \& Blackwell, 1993; Rodríguez, 1995; Schmutterer, 1988, 1990; Warthen Jr., 1989).

O êxito nos trabalhos com nim e o efeito semelhante encontrado em outra meliácea originária da Índia, denominada Melia azedarach e que também possui limonóides com atividade inseticida (McMillian et al., 1969), tem entusiasmado vários grupos de pesquisadores no intuito de encontrar outras espécies de meliáceas e novos compostos com atividade inseticida. 


\subsubsection{Efeito de Trichilia spp. sobre S. frugiperda}

Uma das primeiras referências de uso de Trichilia no controle de S. frugiperda é a de Mikolajczak \& Reed (1987), onde foram avaliados os efeitos da adição de extratos hexânicos e etanólicos de sementes de $T$. connaroides, $T$. prieureana, $T$. roka e $T$. triphyllaria, à dieta artificial fornecida às lagartas. Os autores constataram maior eficiência dos extratos etanólicos de $T$. prieureana e $T$. roka com $100 \%$ de mortalidade e de $T$. connaroides com $80 \%$ de mortalidade. Em relação aos extratos hexânicos, apenas os de $T$. prieureana ( $40 \%$ de mortalidade) apresentaram ação sobre os insetos. Já os extratos de $T$. triphyllaria não apresentaram qualquer efeito sobre a praga.

Villar et al. (1990) avaliaram os efeitos de extratos aquosos de $T$. havanensis e $T$. americana aplicados sobre plantas de milho infestadas com a lagarta-do-cartucho. O rendimento das parcelas tratadas três vezes por semana com os extratos de ambas as espécies foi $100 \%$ superior à média do tratamento testemunha (água + sabão).

Trabalhando com extratos aquosos de $T$. casaretti, $T$. catigua, $T$. claussenii, $T$. elegans e $T$. pallida adicionados à dieta artificial (na concentração de 1\%), Rodríguez \& Vendramim (1996, 1997) encontraram resultados promissores em relação à lagarta-do-cartucho do milho. Os autores constataram que nos tratamentos com ramos de $T$. pallida a mortalidade larval chegou a $100 \%$, sendo que folhas de $T$. casaretti e ramos de $T$. catigua inibiram a alimentação das lagartas, enquanto que ramos de $T$. elegans não apresentaram ação tóxica sobre a praga. Quanto a $T$. claussenii, apenas os ramos afetaram o desenvolvimento da praga, sendo as folhas inócuas ao inseto, o que também ocorreu com as folhas de $T$. catigua. Estimando alguns índices nutricionais, Rodriguez \& Vendramim (1998) constataram que o extrato de ramos de $T$. claussenii induziu o aumento no consumo de dieta pelas lagartas, apesar de não ter havido maior ganho de peso, o que se refletiu em 
menor índice de conversão alimentar dentre quatro espécies de meliáceas testadas.

Os resultados constatados por Rodríguez \& Vendramim (1996) com extratos de caules de $T$. pallida levaram à realização de uma série de trabalhos com esta planta, não só com $S$. frugiperda, mas com outros insetospraga.

O efeito de extratos aquosos de ramos e folhas de $T$. pallida, aplicados diretamente sobre folhas de milho oferecidas à praga, foi avaliado por Torrecillas (1997), sendo constatado, que, em todas as concentrações testadas (1, 3 e $5 \%$ ), o extrato de ramos aumentou a duração da fase larval. Nas concentrações de $5 \%$ e $3 \%$, provocaram mortalidade de $100 \%$ dos insetos nas fases de lagarta e pupa respectivamente. A autora concluiu que os extratos de T. pallida a $5 \%$ apresentam ação inseticida similar ao de sementes de $A$. indica.

$\mathrm{Na}$ avaliação de doses subletais, Torrecillas \& Vendramim (2001), utilizando folhas de milho de um híbrido suscetivel e uma cultivar resistente a $S$. frugiperda, concluíram que, à concentração de $1 \%$, os extratos de $T$. pallida impediram o desenvolvimento da praga na fase larval, mesmo no híbrido suscetivel. Já na menor concentração $(0,1 \%)$, o extrato reduziu o peso e a viabilidade larval, além de alongar as fases larval e pupal. Dentre os parâmetros avaliados, apenas o peso de pupas não foi afetado.

No intuito de aumentar a eficiência dos extratos de $T$. pallida sobre S. frugiperda, Roel et al. (2000a) utilizaram dois solventes orgânicos (metanol e acetona) na obtenção dos extratos, os quais foram aplicados sobre folhas de milho fornecidas às lagartas. Os autores verificaram que os extratos de ramos mesmo na menor concentração $(0,008 \%)$ levaram à mortalidade de $100 \%$ das lagartas até o $8^{\circ}$ dia. Já com os extratos de folhas à concentração de $0,008 \%$, a eficiência foi menor, atingindo 58 e $90 \%$, respectivamente com os extratos acetônico e metanólico. Em razão dos resultados satisfatórios obtidos com o extrato acetônico, foi realizada uma partição do mesmo com hexano e acetato de etila. Os extratos de ramos e folhas obtidos a partir do acetato de etila 
superaram os hexânicos, provocando mortalidade das lagartas, ao $5^{\circ}$ dia, superior a 70\% para as concentrações de 0,2 e 1\% (Roel et al., 2000a).

Utilizando a mesma fração obtida pela partição com acetato de etila proveniente de ramos e folhas de $T$. pallida e fornecendo-a em aplicação sobre folhas de milho a lagartas recém-eclodidas e com 10 dias de idade, Roel et al. (2000b) constataram mortalidade total das larvas na concentração de $0,05 \%$ e aumento significativo da fase larval na concentração de $0,006 \%$. Roel \& Vendramim (1999), avaliando o extrato acetato de etila de ramos e folhas de T. pallida em relação a esta praga, constataram que a $0,001 \%$, embora não tenha afetado a sobrevivência larval, o referido extrato provocou redução no peso de lagartas e pupas, além de ocasionar aumento da fase larval.

A aparente maior eficiência sobre $S$. frugiperda dos extratos orgânicos (Roel et al., 2000a, b; Roel \& Vendramim, 1999) em relação aos aquosos (Torrecillas, 1997; Torrecillas \& Vendramim, 2001) deve-se à diferença no cálculo da concentração. Assim, enquanto os primeiros autores consideraram para o cálculo das concentrações o peso do extrato obtido após a extração e evaporação do solvente, para os últimos a concentração foi estabelecida com base no peso do material bruto (os pós das estruturas vegetais) antes da extração com o solvente, não quantificando, portanto, o material extraído para fins de cálculo da concentração.

\subsubsection{Efeito de Trichilia spp. sobre outros insetos}

T. havanensis é um bom exemplo do emprego de plantas no controle de insetos. Agricultores mexicanos maceram sementes desta planta em água, formando uma pasta que é utilizada para umedecer sementes de milho durante três dias antes do plantio. Com a utilização desta prática, é possivel evitar o ataque de pragas durante a fase de germinação das sementes (Hernández et al., 1983). 
Nakatani et al. (1981) e Nakanishi (1982) isolaram e identificaram quatro limonóides da casca da raiz de $T$. roka os quais foram denominados triquilinas. Estas apresentam efeito de inibição alimentar em Spodoptera eridania, Epilachna varivestis e Choristoneura fumigerana. Também relataram a dificuldade em sintetizar as triquilinas, em escala comercial, dada à complexidade de sua estrutura.

A adição de extratos etanólicos a $0,2 \%$ de $T$. americana, $T$. connaroides, T. glabra, $T$. havanensis, $T$. hirta, $T$. martiana, $T$. pleeana, $T$. quadrijuga e $T$. trifolia à dieta artificial causou significativa redução no crescimento de larvas de Peridroma saucia (Xie et al., 1994), sendo que T. hirta e $T$. connaroides foram as espécies mais efetivas. Xie et al. (1994) também constataram que o extrato da madeira de $T$. hirta causou mortalidade total das lagartas até $\circ 7^{\circ}$ dia. $O$ extrato de folhas não causou mortalidade, porém, ocasionou grande redução do peso $(82,5 \%)$ em relação à testemunha. Fato semelhante ocorreu com $T$. connaroides onde as folhas não causaram mortalidade ao $7^{\circ}$ dia e os extratos da casca afetaram drasticamente o desenvolvimento das larvas $\left(2,1 \%\right.$ do peso da testemunha ao $\left.7^{\circ} \mathrm{dia}\right)$. Xie et al. (1994), ao avaliarem a $\mathrm{CE}_{50}{ }^{2}$, também verificaram que os extratos da casca de $T$. connaroides foram os mais eficientes com $C_{50}$ de 29,1 e 185,1 ppm para $P$. saucia e Spodoptera litura, respectivamente. A hirtina, limonóide extraído de $T$. hirta, inibiu o crescimento larval de $P$. saucia com $C_{50}$ de 13,0 ppm (Xie et al., 1994). Os autores verificaram que tanto a hirtina como diversos extratos de $T$. connaroides (sementes, madeira, casca e epicarpo) reduziram significativamente o crescimento larval e as taxas de consumo das larvas de $P$. saucia e S. litura.

A adição de extratos metanólicos a $1000 \mathrm{ppm}$ de $T$. americana, $T$. glabra, T. hirta, T. martiana, T. pleeana e T. quadrijuga à dieta artificial de larvas

\footnotetext{
${ }^{2}$ Concentração efetiva a qual reduz em $50 \%$ o desenvolvimento larval em relação à testemunha.
} 
de S. litura, também causou significativa redução no crescimento das mesmas (Wheeler et al., 2001). Extratos de $T$. quadrijuga e $T$. glabra reduziram o peso das larvas ao $7^{\circ}$ dia em 95 e $87 \%$, respectivamente. O extrato de $T$. americana foi o mais efetivo reduzindo em $96 \%$ o peso das larvas e sendo o único a causar mortalidade da maioria dos insetos. Em relação ao extrato de ramos de T. americana, Wheeler et al. (2001) constataram redução no crescimento de lagartas com $\mathrm{CE}_{50}$ de $17,2 \mathrm{ppm}$. Já o extrato da madeira ocasionou aumento da duração da fase larval, redução do peso de pupas e adultos, bem como, aumento do número de ínstares nas maiores concentrações (50 e 75 ppm). Wheeler \& Isman (2001) obtiveram resultados semelhantes quando o extrato de $T$. americana foi aplicado sobre folhas de repolho, onde causou redução de $50 \%$ no consumo de folhas nos testes com chance de escolha e afetou os índices nutricionais, mostrando não apenas efeito anti-alimentar como tóxico.

Chauret et al. (1996) observaram ação de extratos etanólicos da madeira e da casca de $T$. hirta inibindo o crescimento de larvas de Ostrinia nubilalis e $P$. saucia. A ação inseticida observada em $T$. hirta é associada à presença de hirtina, já mencionada anteriormente (Xie et al., 1994), porém, outros compostos podem estar associados à ação inseticida dessa espécie. Hantos et al. (2001), fracionando os extratos obtidos por Chauret et al. (1996), isolaram de uma fração com atividade biológica uma substância denominada triquiliasterona. Cortez et al. (1992) também isolaram dois novos limonóides e dois protolimonóides em frutos dessa planta. Entretanto, em ambos os casos a atividade biológica dos compostos não foi avaliada sobre insetos (Hantos et al., 2001; Cortez et al., 1992).

Carmen et al. (2000) testaram extratos e compostos isolados da madeira de $T$. trifolia, os quais, adicionados a discos de farinha de trigo, reduziram significativamente o consumo de Sitophilus oryzae.

Vários limonóides foram isolados de sementes de $T$. havanensis (Arenas \& Rodríguez-Hahn, 1990; Rodríguez-Hahn et al., 1996), sendo a atividade biológica destes testada por Ortego et al. (1999), onde foram 
avaliados azadirone e uma mistura de dois limonóides aplicados sobre folhas de batata oferecidas a larvas de Leptinotarsa decemlineata. A mistura dos limonóides causou mortalidade total $(1000 \mathrm{ppm})$ devido ao efeito tóxico do extrato, bem como, à redução da atividade de proteases e esterases digestivas.

Extratos aquosos de folhas de T. pallida, em concentrações de 1 e $5 \%$, afetaram o desenvolvimento de Tuta absoluta, aumentando a duração e a mortalidade da fase larval e reduzindo o peso de pupas fêmeas (Thomazini et al., 2000). Simmonds et al. (2001) isolaram hirtina e deacetilirtina, além de três novos limonóides de raízes de $T$. pallida. Os compostos extraídos foram avaliados em teste de preferência alimentar sobre lagartas de último ínstar de S. littoralis, S. exigua, Heliothis virescens e Helicoverpa armigera. Apenas um dos novos limonóides isolados causou deterrência em todas as espécies avaliadas. A deacetilirtina apresentou efeito sobre $H$. virescens e $H$. armigera. Os autores também avaliaram o efeito do extrato acetônico de raízes sobre lagartas de $S$. littoralis, que foi o mais eficiente dentre os tratamentos mencionados.

T. pallida também apresenta ação inseticida sobre Bemisia tabaci. Souza \& Vendramim (2000a) constataram que o extrato aquoso a $3 \%$ de ramos desta espécie, quando aplicado sobre ovos e ninfas, causou mortalidade de 38,7 e $53,6 \%$ respectivamente, sem, entretanto, afetar a duração das fases. $\mathrm{Na}$ comparação dos extratos, a $3 \%$, de folhas, ramos e córtex de $T$. pallida, o extrato de ramos foi o mais efetivo no controle dessa praga, causando 41,3 e $43,3 \%$ de mortalidade de ovos e ninfas respectivamente, quando as aplicações foram feitas sobre ambas as fases (Souza \& Vendramim, 2001). Ao avaliarem o efeito de concentrações menores, Souza \& Vendramim (2000b) constataram que concentrações de 1 e $2 \%$ também ocasionam mortalidade de ovos e ninfas de B. tabaci. Embora afetem a viabilidade, em nenhum dos casos mencionados, os extratos aquosos de $T$. pallida afetaram a duração das fases imaturas da praga. 
Diversos compostos com potencial inseticida (limonóides, protolimonóides, triterpenóides etc.) têm sido isolados de diversas espécies e partes de plantas de Trichilia, tais como: do pericarpo de $T$. connaroides (Inada et al., 1994); da casca do caule de $T$. emetica (Gunatilaka et al., 1998) e $T$. estipulata (Cortez et al., 1998, 2000); das raízes de T. rubra (Musza et al., 1995); das folhas de T. hispida (Jolad et al., 1980), T. prieuriana (Olugbade, 1991; Olugbade \& Adesanya, 2000) e T. claussenii (Pupo et al., 1996,1997,1998); da semente e da casca de T. elegans (Garcez et al., 1996, 1997, 2000) e das folhas e raízes de T. schomburgkii (Tinto et al., 1991). A atividade biológica destas plantas, entretanto, ainda não foi testada sobre insetos.

\subsubsection{Efeito de outras meliáceas sobre S. frugiperda}

Extratos clorofórmicos de folhas de Melia azedarach adicionados à dieta artificial nas concentrações de 1 e $3 \%$ causaram mortalidade de 90 e $100 \%$ em lagartas de S. frugiperda, respectivamente (McMillian et al., 1969). Estes extratos não só afetaram a mortalidade como causaram significativas reduções no peso, tamanho e taxa de alimentação das lagartas. Já os extratos aquosos a $10 \%$ de frutos desta planta aplicados sobre folhas de milho afetaram o peso, a viabilidade e a duração da fase larval (Vendramim \& Scampini, 1997).

Mikolajczak \& Reed (1987) constataram que os extratos etanólicos extraídos das sementes de Aglaia cordata, Dysoxylum malabaricum, $D$. reticulatum, D. spectabile, Melia dubia, Sandoricum koetjape e Swietenia mahogani, quando incorporados à dieta artificial de $S$. frugiperda, apresentaram elevada atividade inseticida, causando mortalidade de mais de $80 \%$ da população, com redução de mais de $75 \%$ na taxa de alimentação.

O extrato hexânico de sementes de Carapa procera aplicado sobre discos de feijoeiro causou inibição da alimentação de lagartas de $S$. frugiperda em teste com chance de escolha. Porém, ao incorporá-lo à dieta 
artificial, o mesmo permitiu o desenvolvimento larval até a fase de pupa (Mikolajczak et al., 1988). Os autores identificaram um limonóide presente no óleo das sementes, o qual seria o responsável pela ação deterrente alimentar causada ao inseto.

Powell et al. (1991) extraíram dois limonóides de sementes de $S$. koetjape, identificados como sandoricina e 6-hidroxisandoricina, e testaram o efeito dos mesmos sobre a alimentação de $S$. frugiperda. Constataram significativa inibição da alimentação de ambas as substâncias, mesmo nas menores concentrações (25 ppm).

Mootoo \& Ramasewak (1996) isolaram seis limonóides de sementes de Ruegea glabra os quais provocaram redução da alimentação de larvas de $S$. frugiperda, quando aplicados sobre folhas de milho fornecidas ao inseto em teste de múltipla escolha. Teste semelhante para estudo de deterrência alimentar de compostos vegetais sobre $S$. frugiperda foi desenvolvido por Mootoo et al. (1999), onde, dos vários limonóides isolados, apenas quatro, provenientes de $S$. macrophylla e $S$. aubrevilleana, foram testados sobre o inseto, apresentando efeito inibidor da alimentação.

No Brasil, alguns trabalhos, como o de Rodríguez \& Vendramim (1996, 1997), avaliaram a ação de extratos aquosos de Meliaceae sobre $S$. frugiperda. Além do efeito dos extratos de Trichilia spp. (descritos no item 2.2.2), os autores constataram que a aplicação de extratos aquosos (incorporados à dieta artificial fornecida às lagartas a 1\%) de folhas e ramos de M. azedarach, bem como, de ramos e sementes de Cabralea canjerana e Cedrela fissilis respectivamente, causaram mortalidade total das lagartas. Já os extratos de ramos de $C$. fissilis e de frutos de Guarea guidonia inibiram o desenvolvimento da praga enquanto que o extrato de frutos de $G$. guidonia atuou como inibidor da alimentação. Não foi constatada ação dos extratos aquosos de ramos de G. guidonia, G. kunthiana e G. macrophylla. Ao compararem o efeito dos extratos aquosos a $5 \%$ com extrato de sementes de $A$. indica, cuja ação sobre a lagarta-do-cartucho do milho já era conhecida, os 
autores comprovaram que, embora nenhuma destas meliáceas tenha superado o efeito de $A$. indica, os extratos de sementes de $C$. odorata e de frutos de $M$. azedarach causaram alta mortalidade larval (acima de $80 \%$ ).

Rodríguez \& Vendramim (1998), ao avaliarem o efeito da adição de extratos de algumas meliáceas à dieta artificial, sobre os índices nutricionais de lagartas de $S$. frugiperda, constataram que frutos de $M$. azedarach inibem a ingestão de alimento, acarretando menor peso e alongamento da fase, enquanto que $C$. fissilis não apresentou efeito insetistático e $S$. macrophylla provocou inibição do crescimento em razão da menor conversão do alimento ingerido. 


\section{MATERIAL E MÉTODOS}

Os trabalhos foram conduzidos no Departamento de Entomologia, Fitopatologia e Zoologia Agricola da Escola Superior de Agricultura "Luiz de Queiroz" - Universidade de São Paulo. Numa primeira etapa, foram desenvolvidos bioensaios no Laboratório de Plantas Inseticidas, à temperatura de $25 \pm 1^{\circ} \mathrm{C}$, UR de $70 \pm 10 \%$ e fotofase de 14 horas. Posteriormente, foram realizados os testes de campo na área experimental do Setor de Entomologia, no referido Departamento.

\subsection{Criação dos insetos}

A criação de Spodoptera frugiperda (J.E. Smith) foi iniciada a partir de posturas coletadas no campo. Esta foi mantida no Laboratório de Plantas Inseticidas, onde as lagartas eram alimentadas em dieta artificial de Burton \& Perkins (1972). Periodicamente, era efetuada a reintrodução de novas posturas do campo com o intuito de evitar a degeneração da criação, a qual foi mantida durante todo o periodo dos bioensaios. 


\subsection{Obtenção e preparo do material vegetal}

\subsubsection{Coleta e acondicionamento das partes vegetais}

Foram avaliadas seis espécies de Trichilia (Tabela 1 e Figura 1), utilizando-se como padrão sementes de Azadirachta indica (nim). As estruturas vegetais (ramos, folhas, frutos e/ou sementes) de Trichilia foram obtidas em duas coletas realizadas, respectivamente, em maio de 2001 e janeiro de 2002 . A confirmação das espécies foi feita pela Prof ${ }^{a}$ Ana Odete Santos Vieira do Departamento de Biologia Animal e Vegetal da Universidade Estadual de Londrina. As sementes de nim foram provenientes da Costa Rica.

De cada uma das espécies coletadas, foi depositada uma exsicata (Tabela 1) no herbário do Departamento de Ciências Biológicas, Setor de Sistemática Vegetal, da ESALQ/USP.

Todo material vegetal avaliado nos bioensaios foi seco separadamente em estufa a $40^{\circ} \mathrm{C}$, por 48 horas (para os ramos até 96 horas) e posteriormente triturado em moinho de facas, até obtenção de pó. Após a moagem, o material foi armazenado em vidros hermeticamente fechados e etiquetados com os referidos dados de coleta. 
Tabela 1. Espécies de Trichilia utilizadas nos testes com Spodoptera frugiperda, e seus respectivos locais e datas de coleta, e números de tombo.

\begin{tabular}{llcc}
\hline Espécie & Local de coleta & $\begin{array}{c}\text { Data de } \\
\text { coleta }\end{array}$ & $\begin{array}{c}\mathrm{N}^{\circ} \text { de } \\
\text { tombo }\end{array}$ \\
\hline Trichilia casaretti & Fazenda Doralice, Londrina, PR & $08 / 05 / 01$ & ESA \\
& & $08 / 01 / 02$ & 81284 \\
Trichilia catigua & Fazenda Doralice, Londrina, PR & $08 / 05 / 01$ & ESA \\
& & $08 / 01 / 02$ & 81285 \\
Trichilia claussenii & Parque Estadual Mata dos Godoy, Londrina, PR & $08 / 05 / 01$ & ESA \\
& Lajeado das Orquídeas, Sapopema, PR & $08 / 01 / 02$ & 81289 \\
Trichilia elegans & Fazenda Doralice, Londrina, PR & $08 / 05 / 01$ & ESA \\
& & $08 / 01 / 02$ & 81287 \\
Trichilia pallens & Parque Estadual Mata dos Godoy, Londrina, PR & $08 / 05 / 01$ & ESA \\
& Lajeado das Orquideas, Sapopema, PR & $08 / 01 / 02$ & 81286 \\
Trichilia pallida & Fazenda Doralice, Londrina, PR & $08 / 05 / 01$ & ESA \\
& & $08 / 01 / 02$ & 81288 \\
\hline
\end{tabular}

${ }^{\top}$ Número de tombo da exsicata no herbário do Departamento de Ciências Biológicas da ESALQ/USP 

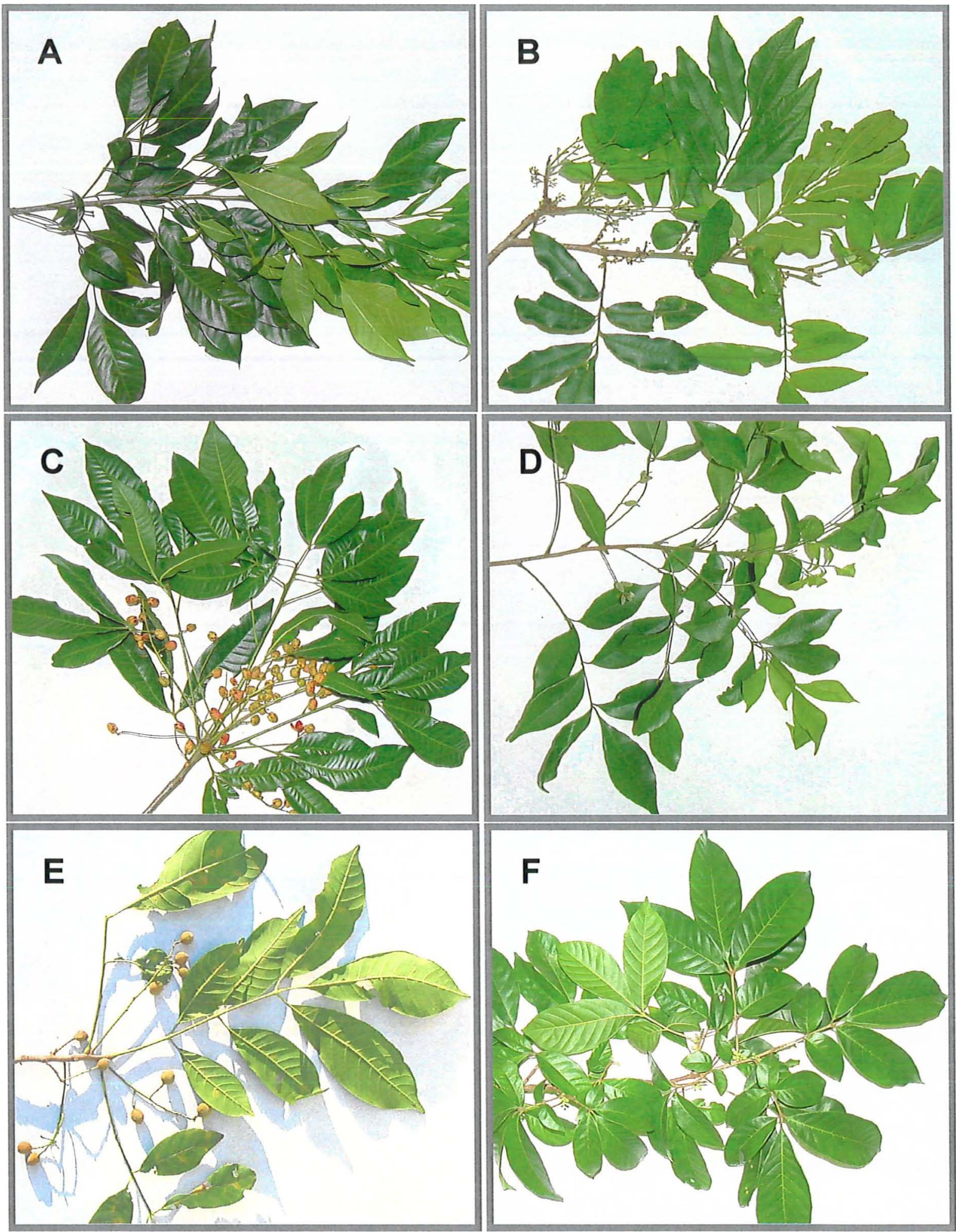

Figura 1 - Espécies de Trichilia utilizadas nos testes com Spodoptera frugiperda: A - T. casaretti; B - T. catigua; C - T. claussenii; D - T. elegans; E - T. pallens; F - T. pallida. 


\subsubsection{Preparação dos extratos}

O solvente utilizado para extração dos compostos com atividade inseticida foi a água. Para preparo do extrato, houve imersão do pó (das estruturas vegetais) em água destilada, agitação para homogeneizar a amostra, manutenção por 24 horas em repouso no solvente para extração e posterior filtragem com tecido fino de voil para retirada do material sólido. Os extratos prontos foram utilizados em um periodo não superior a 48 horas após o preparo.

As concentrações utilizadas estão expressas em percentual, levando em consideração o peso/volume de material (pó) inicialmente imerso na água, e não a quantidade de extrato efetivamente contido na solução.

\subsubsection{Cultivo de milho}

Mensalmente, durante todo o período dos testes, foi efetuado no campo o plantio de milho para fornecimento das folhas a serem utilizadas nos bioensaios laboratoriais. Nas épocas de escassez de chuvas, a área cultivada foi irrigada. Dependendo do estádio fenológico das plantas no campo, foram feitos alguns plantios adicionais.

O híbrido utilizado foi o XL 269. As práticas de manejo utilizadas foram as preconizadas para a cultura, porém, sem a utilização de defensivos agricolas, que pudessem interferir no desenvolvimento dos testes.

\subsection{Bioensaios}

Os testes foram divididos em duas etapas. Na primeira etapa foram realizados ensaios laboratoriais no intuito de avaliar os efeitos dos extratos na sobrevivência e desenvolvimento do inseto, bem como, no consumo de folhas de milho pelas lagartas. Na segunda etapa foram selecionados os 
melhores tratamentos nos ensaios laboratoriais para os testes em condições de campo.

\subsubsection{Bioensaios de laboratório}

Para realização dos bioensaios laboratoriais, foram utilizadas folhas de milho coletadas no campo na fase vegetativa da cultura. Sempre foi coletada a terceira folha da planta a contar do ápice para a base, no intuito de utilizar as folhas mais jovens e obter material mais homogêneo.

No laboratório, as folhas eram enxaguadas para retirada de partículas mais grosseiras e colocadas em um recipiente com água para hidratação. Já hidratadas, as folhas eram cortadas em pedaços de $12 \mathrm{~cm}^{2}$ de área, $3 \times 4 \mathrm{~cm}$ aproximadamente, sendo cortados, no máximo, três pedaços por folha a contar da base do limbo, no intuito de usar a parte mais tenra da mesma. Após o corte, estas eram distribuídas sobre papel toalha para evaporação da água superficial.

As folhas já secas eram imersas na solução aquosa contendo o extrato por aproximadamente cinco segundos, sendo a seguir mantidas em condição ambiente para evaporação do excesso de liquido.

As folhas tratadas com extrato $e$ as folhas da testemunha (tratadas com água destilada) foram mantidas em tubos de vidro de $2,5 \mathrm{~cm}$ de diâmetro x $8,5 \mathrm{~cm}$ de altura, onde foram colocadas três lagartas (com exceção do bioensaio 3.3.1.2, onde as lagartas foram individualizadas). As folhas eram substituidas diariamente por novas folhas tratadas.

As lagartas utilizadas em todos os testes permaneceram por 24 horas em dieta artificial após a eclosão. Esta prática foi utilizada para reduzir a morte das lagartas por manipulação e desidratação durante a instalação dos bioensaios. 
3.3.1.1 Efeito dos extratos de seis espécies de Trichilia e de Azadirachta indica na sobrevivência e peso larval ao $5^{\circ}$ dia de $S$. frugiperda

Neste teste, foram utilizados extratos aquosos, na concentração de $5 \%$, de ramos e folhas das seis espécies de Trichilia, de frutos verdes e maduros de $T$. pallens, e de sementes de nim, A. indica (padrão). Como testemunha foram utilizadas folhas de milho tratadas com água destilada.

Foi avaliada a mortalidade diária e o peso ao $5^{\circ}$ dia após a instalação do bioensaio. Para cada extrato (tratamento) obtido, foram utilizadas 90 lagartas, distribuídas em dois blocos com três repetições de 15 lagartas cada.

\subsubsection{Efeito dos extratos de seis espécies de Trichilia sobre o desenvolvimento do inseto}

Neste teste foram utilizados extratos na concentração de $1 \%$ de ramos e folhas das seis espécies de Trichilia, para avaliar os efeitos dos mesmos sobre o desenvolvimento do inseto.

As variáveis biológicas avaliadas foram: peso das lagartas ao $8^{\circ} \mathrm{e}$ $14^{\circ}$ dia após a instalação; duração e mortalidade diária da fase larval; duração e mortalidade da fase pupal; peso de pupas; e porcentagem de deformação de adultos.

Foram utilizadas 90 lagartas por tratamento, distribuidas em dois blocos com três repetições de 15 lagartas cada. 


\subsubsection{Preferência de lagartas por folhas de milho tratadas e não tratadas com extratos de Trichilia spp.}

Neste ensaio foram avaliados os extratos de ramos e folhas das seis espécies de Trichilia. Para cada espécie e estrutura vegetal foi realizado um teste com chance de escolha entre substrato (folha de milho) tratado com o extrato correspondente e substrato não tratado.

Os testes foram desenvolvidos em placas de Petri de $15 \mathrm{~cm}$ de diâmetro, com o fundo recoberto por uma camada de gesso com aproximadamente $0,5 \mathrm{~cm}$ de espessura. Sobre o gesso previamente umedecido na placa, colocou-se uma folha de papel filtro de mesmo diâmetro e sobre este fixaram-se, com alfinetes, discos de folhas de milho de $2,9 \mathrm{~cm}$ de diâmetro, obtidos com vazador. Foram colocados quatro discos de folhas por placa, sendo dois tratados com o extrato a ser testado e dois tratados com água destilada (padrão), dispostos aos pares de forma cruzada e eqüidistantes. Cada disco foi identificado pela cor do alfinete (branca para o disco com o extrato e preta para o padrão) (Figura 2).

No centro de cada placa foi liberada uma lagarta de quarto ínstar (mantida até então em dieta artificial) num ponto eqüidistante dos discos foliares (Figura 2).

Após 24 horas, as lagartas foram retiradas e a área dos discos foi medida com um integrador de área foliar ( $\mathrm{Li}$-Cor, modelo LI-3000A). O consumo foliar por lagarta foi obtido pela diferença entre a área inicial da folha e a área que sobrou. 


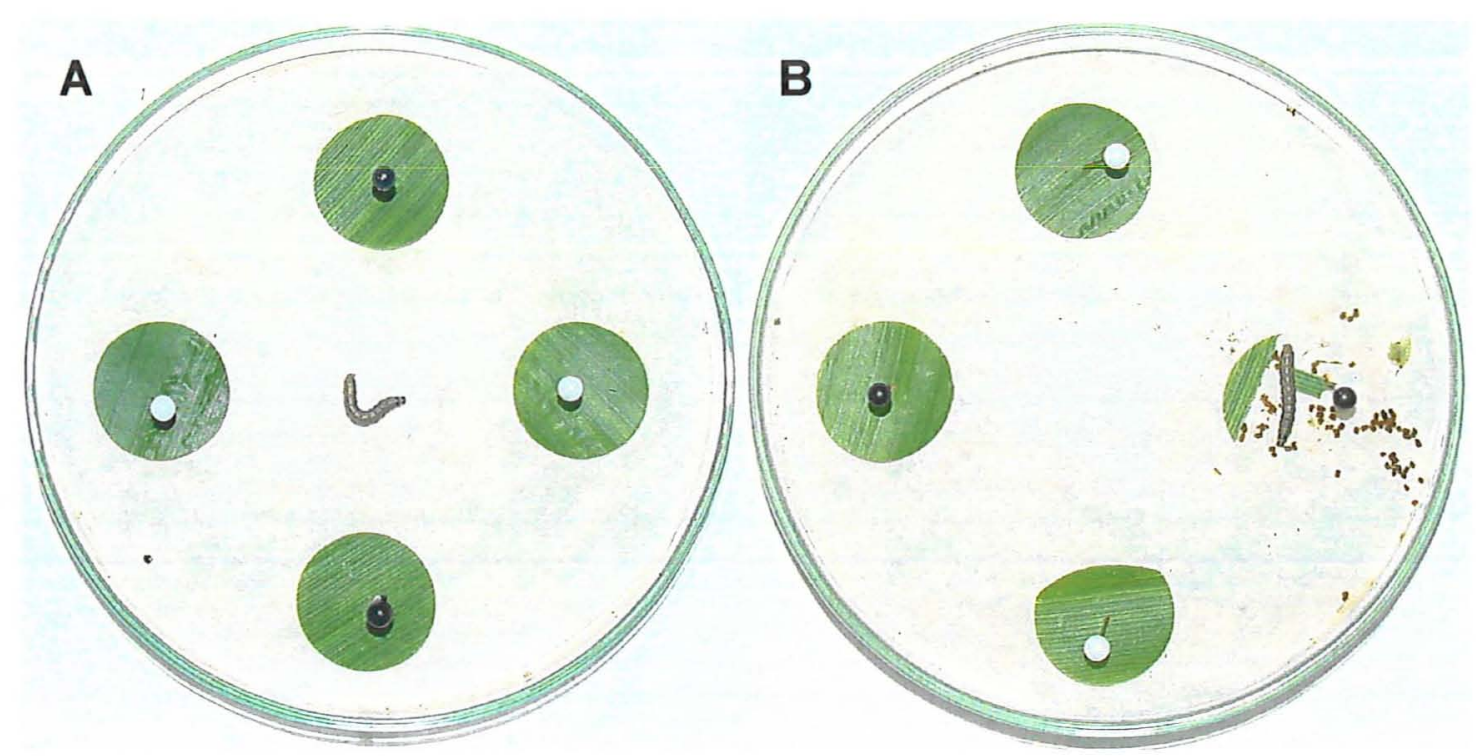

Figura 2 - Placas utilizadas em teste de consumo de folhas de milho por lagartas de Spodoptera frugiperda. Discos de folhas distribuídos na placa, imediatamente após a liberação da lagarta (A) e 24 horas após (B).

Com base nos valores das áreas consumidas por lagarta, foi calculado o índice de preferência adaptado de Kogan \& Goeden (1970), conforme a seguinte equação:

$I P=2 A / M+A$, onde

IP = Índice de preferência;

$A=$ Área consumida no disco de folha tratado com o extrato;

$\mathrm{M}=$ Área consumida no disco de folha padrão.

Os valores do IP variam entre zero e dois sendo que:

$\mathrm{IP}=1$, indica efeito neutro

$I P>1$, indica efeito fago-estimulante

$\mathrm{IP}<1$, indica efeito deterrente (fago-deterrente) 
Como margem de segurança para esta classificação, o erro padrão da média (EP) foi adicionado/subtraído do índice 1,00 (indicativo de neutralidade). Assim, o efeito deterrente ou fago-estimulante de cada extrato só foi considerado quando o IP do mesmo estava fora do intervalo 1,00 \pm EP.

Para cada extrato vegetal foram utilizadas 15 placas, cada uma representando uma repetição.

\subsubsection{Bioensaio de campo}

Foram instaladas na área experimental do Setor de Entomologia, 28 parcelas de milho, distribuídas em quatro blocos com sete parcelas cada. Cada parcela foi composta por cinco linhas de plantas, com $4 \mathrm{~m}$ de comprimento e $0,9 \mathrm{~m}$ de espaçamento entre linhas. As duas linhas externas e um metro em cada extremidade da parcela foram deixados como bordadura, utilizando-se para avaliação, apenas a área central da parcela.

A semeadura do milho (híbrido $A G$ 1051) foi realizada manualmente em 19/08/02. No estádio de plântula, foi feito o desbaste de modo a manter uma população de cerca de 60.000 plantas por ha. Sempre que necessário, a área era irrigada para permitir o normal desenvolvimento da cultura.

Para garantir infestação uniforme de lagartas na área, as plantas, no estádio de 7 a 8 folhas, foram infestadas artificialmente com a utilização de uma "bazuca" (Wiseman et al., 1980), no qual lagartas recém-eclodidas estavam misturadas com sabugo de milho seco moído. O equipamento foi calibrado para colocar 15 lagartas por planta, sendo a infestação realizada apenas nas plantas da área útil da parcela.

Os tratamentos testados foram:

1) Testemunha (água);

2) Extrato aquoso de folhas de T. pallens;

3) Extrato aquoso de ramos de T. pallens; 
4) Extrato aquoso de ramos de T. pallida;

5) Extratos aquosos de sementes de $A$. indica;

6) Óleo de nim a 0,5\%; e

7) Lufenuron (Match $\left.{ }^{\circledR} \mathrm{CE}-300 \mathrm{ml} / \mathrm{ha}\right)$.

Os extratos aquosos foram utilizados na concentração de $6,7 \%$, sendo esta baseada na literatura sobre nim que recomenda o uso de $20 \mathrm{~kg}$ de semente por hectare, para controle de pragas (Dreyer, /199/).

As aplicações foram realizadas com pulverizador costal pressurizado com $\mathrm{CO}_{2}$, equipado com bico tipo leque 8004 em jato dirigido sobre a linha de plantas, com volume de calda de $300 \mathrm{l} / \mathrm{ha}$, à pressão de 32 $\mathrm{lb} / \mathrm{pol}^{2}$.

A avaliação do dano causado pelas lagartas às plantas foi realizada utilizando uma escala de notas de 1 a 5 (Cruz, 1980), onde: 1 nenhum dano, 2 - folhas raspadas, 3 - folhas furadas, 4 - folhas rasgadas e com dano no cartucho e, 5 - cartucho destruído.

Foram realizadas três avaliações em intervalo semanal, sendo a primeira realizada em 24/09/02 (antes da pulverização). As plantas a serem avaliadas em cada parcela foram previamente identificadas com plaquetas de 5 $x 15 \mathrm{~cm}$ mantidas junto à planta no solo. Os tratamentos foram aplicados logo após a primeira avaliação de dano e 10 dias após (24/09/02 e 04/10/02, respectivamente). A pulverização foi efetuada ao entardecer, para reduzir a exposição dos produtos à luz, pressupondo-se que os compostos contidos nos mesmos são pouco foto-estáveis.

O delineamento utilizado foi em blocos ao acaso com quatro repetições 


\subsection{Análise estatistica}

Os resultados dos ensaios foram submetidos à análise de variância, e quando evidenciada diferença significativa entre as médias ao nivel de $5 \%$ de probabilidade de erro, efetuou-se a complementação da análise através da comparação entre médias pelo teste de Duncan.

Para verificação da homocedasticidade, os ensaios foram submetidos ao teste de Hartley, e nos casos em que se constatou heterocedasticidade, os dados foram submetidos à transformação mais adequada. 


\section{RESULTADOS E DISCUSSÃO}

\subsection{Bioensaios de laboratório}

4.1.1 Efeito dos extratos de meliáceas na sobrevivência e peso larval ao $5^{\circ}$ dia de Spodoptera frugiperda (J.E. Smith)

\subsubsection{Efeito de extratos de folhas e ramos de seis espécies de Trichilia e de sementes de Azadirachta indica}

Dentre os extratos aquosos de folhas das seis espécies de Trichilia testadas, apenas o de T. pallens afetou a sobrevivência das lagartas de S. frugiperda. Neste tratamento, a mortalidade, no $5^{\circ}$ dia, atingiu $98,7 \%$, mesmo valor registrado com o extrato de sementes de nim, Azadirachta indica, incluido no presente trabalho como padrão de eficiência. Para as demais espécies de Trichilia, os valores de mortalidade variaram de 1,3 a $7,0 \%$ e não diferiram do obtido na testemunha (água destilada) $(4,2 \%)$ (Tabela 2 ).

Quanto ao peso de lagartas, apenas o extrato de $T$. catigua não afetou o peso de lagartas, já que esse foi o único tratamento em que o peso larval $(4,7 \mathrm{mg})$ não diferiu do encontrado na testemunha $(6,0 \mathrm{mg})$ (Tabela 2). Os efeitos mais drásticos foram novamente constatados com os extratos de sementes de nim e de folhas de $T$. pallens, nos quais os valores obtidos $(0,4 \mathrm{e}$ $0,5 \mathrm{mg}$, respectivamente) foram inferiores aos registrados em todos os outros tratamentos. Em relação às demais espécies, em ordem decrescente de 
eficiência, considerando-se o efeito sobre o ganho de peso pelas lagartas, situaram-se $T$. casaretti (1,3mg), $T$. elegans $(2,0 \mathrm{mg}), T$. pallida $(2,2 \mathrm{mg})$ e $T$. claussenii $(3,5 \mathrm{mg})$ (Tabela 2$)$.

Tabela 2. Mortalidade e peso de lagartas de Spodoptera frugiperda, ao $5^{\circ}$ dia, alimentadas com folhas de milho tratadas com extratos aquosos, a $5 \%$, de folhas de Trichilia spp. e de sementes de nim.

\begin{tabular}{lcc}
\hline Tratamentos & Mortalidade $(\%)^{1}$ & Peso $(\mathrm{mg})^{1}$ \\
\hline Testemunha & $4,2 \mathrm{~b}$ & $6,0 \mathrm{a}$ \\
T. casaretti & $1,3 \mathrm{~b}$ & $1,3 \mathrm{~d}$ \\
T. catigua & $3,1 \mathrm{~b}$ & $4,7 \mathrm{a}$ \\
T. claussenii & $5,3 \mathrm{~b}$ & $3,5 \mathrm{~b}$ \\
T. elegans & $4,1 \mathrm{~b}$ & $2,0 \mathrm{c}$ \\
T. pallens & $98,7 \mathrm{a}$ & $0,5 \mathrm{e}$ \\
T. pallida & $7,0 \mathrm{~b}$ & $2,2 \mathrm{c}$ \\
Sementes de nim & $98,7 \mathrm{a}$ & $0,4 \mathrm{e}$ \\
\hline
\end{tabular}

${ }^{1}$ Médias seguidas pela mesma letra não diferem entre si pelo teste de Duncan a $5 \%$ de probabilidade de erro.

Ao avaliar o efeito de extratos aquosos de ramos destas espécies, verificou-se que nenhuma espécie atingiu os níveis de mortalidade obtidos com o extrato de sementes de nim, no qual ocorreu mortalidade total das lagartas (Tabela 3). Dentre as espécies de Trichilia, os maiores efeitos foram obtidos com T. pallens e T. pallida, cujos extratos causaram mortalidade de 48,9 e $39,5 \%$, respectivamente, superando os valores obtidos com as demais espécies. O extrato de $T$. elegans causou mortalidade de $7,6 \%$ das lagartas e também superou $o$ valor obtido na testemunha $(1,2 \%)$. Para as demais espécies, as mortalidades registradas $(3,9 \%$ em $T$. claussenii; $2,5 \%$ em $T$. 
casaretti e 2,3\% em $T$. catigua) não diferiram significativamente das observadas na testemunha e em T. elegans (Tabela 3 ).

A mesma tendência foi observada com as variações no peso das lagartas, constatando-se os menores valores com os extratos de T. pallida e $T$. pallens $(1,0$ e $1,2 \mathrm{mg}$ por lagarta, respectivamente), os quais diferiram das médias obtidas nos demais extratos. Os pesos larvais obtidos nas demais espécies de Trichilia (variáveis entre 2,6 e 3,4mg) não diferiram entre si, mas foram inferiores ao registrado na testemunha $(4,0 \mathrm{mg})$, com exceção apenas do valor encontrado em $T$. casaretti $(3,4 \mathrm{mg})$ (Tabela 3$)$.

Tabela 3. Mortalidade e peso de lagartas de Spodoptera frugiperda, ao $5^{\circ}$ dia, alimentadas com folhas de milho tratadas com extratos aquosos, a $5 \%$, de ramos de Trichilia spp. e de sementes de nim.

\begin{tabular}{lcc}
\hline Tratamentos & Mortalidade $(\%)^{1}$ & Peso $(\mathrm{mg})^{1}$ \\
\hline Testemunha & $1,2 \mathrm{~d}$ & $4,0 \mathrm{a}$ \\
T. casaretti & $2,5 \mathrm{~cd}$ & $3,4 \mathrm{ab}$ \\
T. catigua & $2,3 \mathrm{~cd}$ & $2,6 \mathrm{~b}$ \\
T. claussenii & $3,9 \mathrm{~cd}$ & $2,6 \mathrm{~b}$ \\
T. elegans & $7,6 \mathrm{c}$ & $2,9 \mathrm{~b}$ \\
$T$. pallens & $48,9 \mathrm{~b}$ & $1,2 \mathrm{C}$ \\
T. pallida & $39,5 \mathrm{~b}$ & $1,0 \mathrm{C}$ \\
Sementes de nim & $100,0 \mathrm{a}$ & -- \\
\hline
\end{tabular}

${ }^{1}$ Médias seguidas pela mesma letra não diferem entre si pelo teste de Duncan a $5 \%$ de probabilidade de erro.

Avaliando o efeito de extratos aquosos adicionados em dieta artificial, na concentração de 1\%, Rodríguez \& Vendramim $(1996,1997)$ não observaram efeito de folhas e caules (ramos) de quatro espécies de Trichilia ( $T$. elegans, $T$. claussenii, $T$. casaretti e $T$. catigua) sobre a viabilidade larval de $S$. 
frugiperda. Estes resultados foram semelhantes aos obtidos neste trabalho, onde a mortalidade das lagartas ao $5^{\circ}$ dia não foi afetada por estas mesmas espécies de meliáceas, com exceção de ramos de $T$. elegans, que, ainda assim, causou baixa mortalidade larval $(7,6 \%$ ) (Tabela 2 ).

Considerando-se conjuntamente os extratos de folhas e ramos de $T$. casaretti, $T$. catigua, $T$. claussenii e $T$, elegans, verifica-se que embora os efeitos provocados não tenham sido muito pronunciados, ao menos uma das estruturas de cada espécie afetou o peso das lagartas ao $5^{\circ}$ dia (Tabelas 2 e 3 ). Os efeitos causados por $T$. elegans e $T$. claussenii podem estar associados a um ou mais compostos orgânicos já isolados e identificados em sementes de $T$. elegans (Garcez et al., 1996, 1997, 2000) e em caules, folhas e frutos de $T$. claussenii (Pupo et al., 1996, 1997, 1998). A atividade inseticida destes compostos, entretanto, ainda não foi testada.

\subsubsection{Efeito de extratos de folhas e ramos de T. pallida e T. pallens}

Devido aos bons resultados obtidos com $T$. pallida e $T$. pallens (Tabelas 2 e 3), os testes foram repetidos com os extratos aquosos de ramos e folhas de ambas as espécies.

Em todos os tratamentos, a mortalidade larval foi significativamente maior que a registrada na testemunha (Tabela 4). As folhas de $T$. pallens causaram mortalidade total das lagartas, superando os demais tratamentos. Os ramos de ambas as espécies mostraram-se promissores, causando mortalidade superior a $73 \%$ e superando o tratamento com folhas de T. pallida que matou $21,4 \%$ dos insetos.

Em relação ao peso das lagartas, desconsiderando-se o extrato de folhas de $T$. pallens onde nenhuma lagarta tinha sobrevivido, no $5^{\circ}$ dia, a maior eficiência foi constatada com ramos de $T$. pallida, onde o peso larval foi de $0,6 \mathrm{mg}$, valor significativamente menor que os encontrados em ramos de $T$. pallens $(1,0 \mathrm{mg})$ e folhas de $T$. pallida $(1,1 \mathrm{mg})$, ocorrendo nestes três 
tratamentos valores menores que na testemunha (2,6mg) (Tabela 4). Embora estes dados sejam diferentes dos observados no teste anterior (Tabela 3 ), onde os extratos de ramos das duas espécies haviam causado efeito semelhante sobre o ganho de peso, se observa que, também naquele teste, houve tendência de menor peso larval em ramos de T. pallida.

Tabela 4. Mortalidade e peso de lagartas de Spodoptera frugiperda, ao $5^{\circ}$ dia, alimentadas com folhas de milho tratadas com extratos aquosos, a $5 \%$, de ramos e folhas de Trichilia pallida e T. pallens.

\begin{tabular}{llcc}
\hline \multicolumn{2}{c}{ Tratamentos } & Mortalidade $(\%)^{1}$ & ${\text { Peso }(\mathrm{mg})^{1}}^{1}$ \\
\hline \multicolumn{2}{c}{ Testemunha } & $1,7 \mathrm{~d}$ & $2,6 \mathrm{a}$ \\
\multirow{4}{*}{ T. pallens } & Folhas & $100,0 \mathrm{a}$ & - \\
& Ramos & $75,5 \mathrm{~b}$ & $1,0 \mathrm{~b}$ \\
\multirow{4}{*}{ T. pallida } & Folhas & $21,4 \mathrm{c}$ & $1,1 \mathrm{~b}$ \\
& Ramos & $73,9 \mathrm{~b}$ & $0,6 \mathrm{c}$ \\
\hline
\end{tabular}

\footnotetext{
${ }^{1}$ Médias seguidas pela mesma letra não diferem entre si pelo teste de Duncan a $5 \%$ de probabilidade de erro.
}

Os pesos inferiores e mortalidades superiores verificados no segundo bioensaio (Tabela 4) em relação ao primeiro (Tabelas 2 e 3 ) podem estar relacionados ao fato de as folhas de milho no segundo experimento terem sido provenientes de plantas próximas à fase de floração, sendo, portanto, mais duras e, consequentemente, menos favoráveis à alimentação, o que pode ser deduzido quando se observa o menor peso de lagartas na testemunha deste ensaio em relação ao anterior.

A maior eficiência de ramos de T. pallida em relação às folhas, afetando a mortalidade de lagartas de $S$. frugiperda (Tabela 4), também foi constatada por Torrecillas (1997) utilizando extratos aquosos e por Roel et al. (2000a) usando extratos metanólicos, aplicados sobre folhas de milho. 
A ação de $T$. pallida sobre lagartas de $S$. frugiperda está de acordo com os resultados obtidos por Rodríguez \& Vendramim (1996), que constataram mortalidade total em lagartas alimentadas com dieta contendo extrato tanto de folhas quanto de ramos. Resultados semelhantes foram verificados quando folhas de milho foram tratadas com extratos aquosos (Torrecillas \& Vendramim, 2001) e orgânicos (Roel \& Vendramim, 1999; Roel et al., 2000a, b) desta espécie de meliácea. Além de $S$. frugiperda, a ação de $T$. pallida também já foi comprovada em relação a Tuta absoluta (Thomazini et al., 2000) e Bemisia tabaci (Souza \& Vendramim, 2000a, b, 2001).

A exemplo do que tinha sido observado no primeiro bioensaio, também neste, a maior eficiência foi constatada com o extrato de folhas de $T$. pallens provocando, neste bioensaio, mortalidade total das lagartas ao $5^{\circ}$ dia do teste. Cabe ressaltar que este é o primeiro relato de atividade inseticida desta meliácea, já que, até então, não existia qualquer informação de bioatividade em relação a qualquer espécie de inseto.

\subsubsection{Efeito de extratos de diversas estruturas vegetais de $T$. pallens}

Pode-se constatar que, embora os frutos (verdes e maduros) de $T$. pallens apresentem ação inseticida sobre as lagartas, este efeito é menos intenso que o causado por folhas e ramos dessa planta (Tabela 5).

Assim, enquanto os extratos de folhas e ramos, juntamente com o extrato de sementes de nim, provocaram elevada mortalidade larval (100,0; 81,4 e $96,5 \%$, respectivamente), os valores de mortalidade em frutos maduros e verdes foram significativamente menores (40,3 e $29,2 \%$, respectivamente), embora também tenham diferido significativamente do valor constatado em folhas tratadas com água destilada (testemunha) $(2,4 \%)$. Na comparação entre os três tratamentos mais eficientes, os resultados confirmaram os bioensaios anteriores em que se verificou eficiência semelhante de folhas de T. pallens e 
sementes de nim, sendo ambos mais eficientes que o extrato de ramos da primeira meliácea (Tabelas 2, 3 e 4).

Nos tratamentos em que foi possível aferir-se o peso larval ao $5^{\circ}$ dia (em folhas de T. pallens, isso não possivel porque nessa idade todas as lagartas já estavam mortas), os menores valores foram registrados com os extratos de ramos de $T$. pallens e de sementes de nim $(0,77$ e $0,88 \mathrm{mg}$, respectivamente), os quais diferiram daqueles observados em extratos de frutos verdes $(2,44 \mathrm{mg})$ e maduros $(2,60 \mathrm{mg})$, os quais não diferiram entre si, mas foram superiores ao encontrado na testemunha $(6,69 \mathrm{mg})$ (Tabela 5).

Tabela 5. Mortalidade e peso de lagartas de Spodoptera frugiperda, ao $5^{\circ} \mathrm{dia}$, alimentadas com folhas de milho tratadas com extratos aquosos, a $5 \%$, de Trichilia pallens e de sementes de nim.

\begin{tabular}{lcc}
\hline Tratamentos & Mortalidade $(\%)^{1}$ & Peso $(\mathrm{mg})^{1}$ \\
\hline Testemunha & $2,4 \mathrm{~d}$ & $6,69 \mathrm{a}$ \\
Folhas & $100,0 \mathrm{a}$ & -- \\
Frutos maduros & $40,3 \mathrm{c}$ & $2,60 \mathrm{~b}$ \\
Frutos verdes & $29,2 \mathrm{c}$ & $2,44 \mathrm{~b}$ \\
Ramos & $81,4 \mathrm{~b}$ & $0,77 \mathrm{c}$ \\
Sementes de nim & $96,5 \mathrm{a}$ & $0,88 \mathrm{c}$ \\
\hline
\end{tabular}

${ }^{1}$ Médias seguidas pela mesma letra não diferem entre si pelo teste de Duncan a $5 \%$ de probabilidade de erro.

\subsubsection{Efeito dos extratos de seis espécies de Trichilia sobre o desenvolvimento do inseto.}

Para avaliar os efeitos dos extratos de folhas e ramos de Trichilia sobre o desenvolvimento de $S$. frugiperda, foi realizado ensaio utilizando os 
extratos a $1 \%$. A redução na concentração em relação ao bioensaio anterior (item 4.1.1), teve por objetivo permitir que os insetos chegassem à fase adulta, possibilitando assim a mensuração de possíveis efeitos dos extratos nas fases larval, pupal e adulta (ocorrência de deformações).

\subsubsection{Fase larval}

Observando-se a mortalidade larval diária (Figura 3), verifica-se que as folhas de $T$. pallens e ramos de $T$. pallida se destacaram entre os tratamentos, chegando a mortalidade ao final do período a superar os $90 \%$, embora, até $\mathrm{o} 10^{\circ}$ dia apenas o extrato de folhas de $T$. pallens tenha se destacado (quase $45 \%$ de mortalidade, nesta avaliação) enquanto um total de 8 tratamentos (entre os quais ramos de $T$. pallida) estavam provocando mortalidades semelhantes e variáveis entre 10 e $20 \%$. O extrato de folhas de $T$. catigua também causou mortalidade relativamente alta no início da fase larval, embora esta não tenha sido tão pronunciada ao final da fase. Em relação aos demais tratamentos, não se constataram variações expressivas durante o periodo (inclusive para ramos de T. pallens e folhas de T. catigua), embora ao final do mesmo todos tenham causado mortalidade superior à observada na testemunha.

Ao $7^{\circ}$ dia após o inicio de fornecimento de folhas de milho tratadas às lagartas, apenas os tratamentos com extratos de ramos e folhas de $T$. pallens diferiram da testemunha $(2,6 \%)$, sendo que o extrato de folhas matou $39,4 \%$ das lagartas, superando assim os demais tratamentos, inclusive 0 extrato de ramos $(17,2 \%)$. Embora, os ramos desta espécie tenham causado mortalidade superior à testemunha, esta não diferiu significativamente das verificadas nas demais espécies $(5,3$ a $12,9 \%)$, com exceção de ramos de $T$. elegans, que matou apenas $4,2 \%$ das lagartas (Tabela 6 ). 

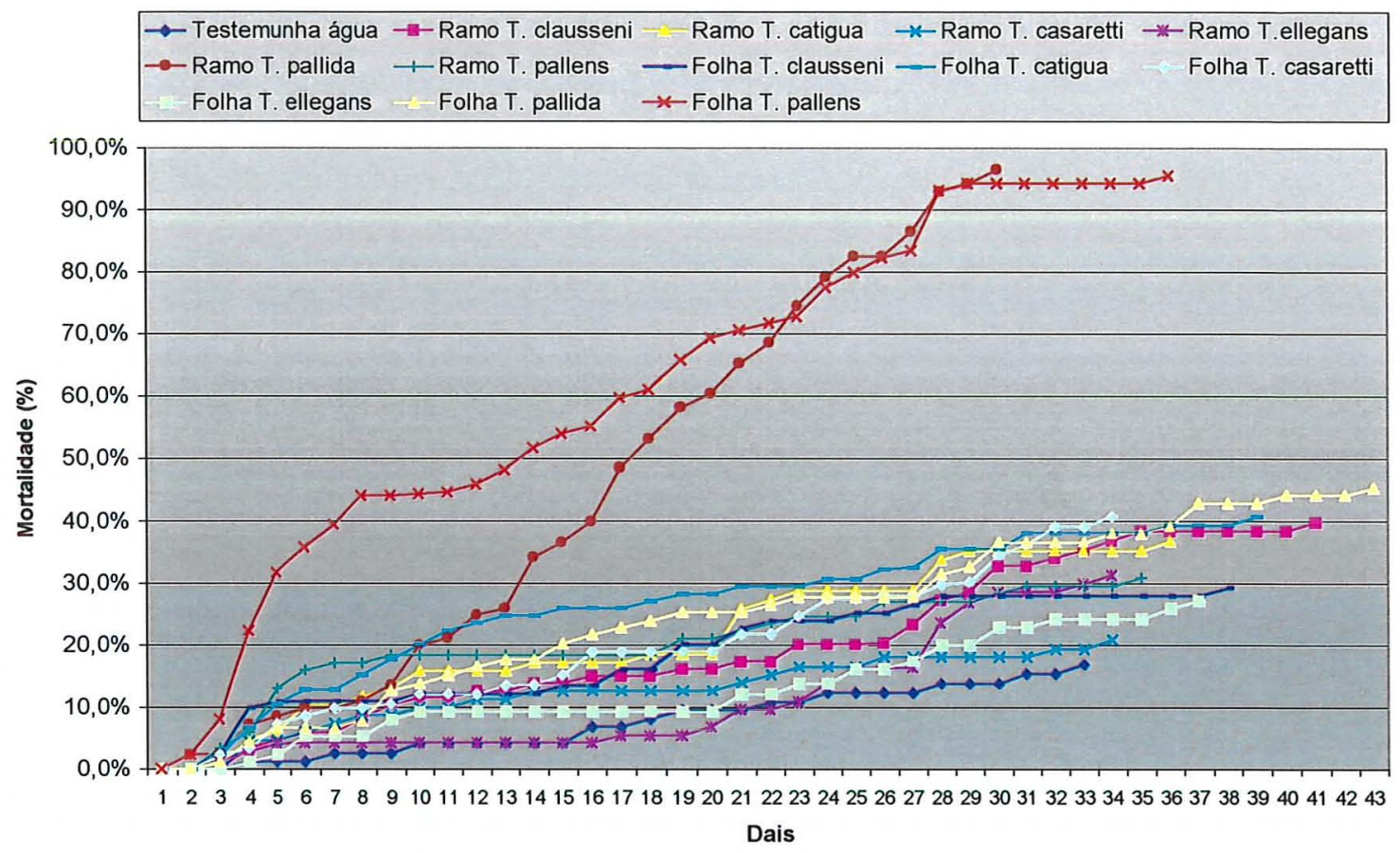

Figura 3 - Mortalidade diária de lagartas de Spodoptera frugiperda alimentadas com folhas de milho tratadas com extratos aquosos, a $1 \%$, de ramos e folhas de Trichilia spp.

Ao $14^{\circ}$ dia, o tratamento mais eficiente continuou sendo o extrato de folhas de T. pallens, o qual foi o único a matar mais de $50 \%$ das lagartas neste período (Tabela 6). Porém, ao contrário do que foi verificado no $7^{\circ} \mathrm{dia}$, os extratos de ramos de $T$. pallida e de folhas de $T$. catigua também superaram a testemunha (4,2\%), provocando mortalidades de 34,1 e $24,9 \%$, respectivamente. A mortalidade no tratamento com ramos de $T$. pallida foi a que mais aumentou proporcionalmente em relação à primeira avaliação, passando a diferir significativamente dos demais tratamentos com exceção de ramos de $T$. pallens $(18,5 \%)$, folhas de $T$. pallida $(17,7 \%)$, e folhas e ramos de $T$. catigua (24,9 e $17,2 \%$, respectivamente). A mortalidade em folhas de $T$. catigua, entretanto, superou apenas os valores constatados no tratamento com ramos de $T$. elegans $(4,2 \%)$ e na testemunha. Apesar de em alguns tratamentos (folhas de $T$. pallida, ramos de $T$. pallens e $T$. catigua) ter ocorrido mortalidade 
cerca de quatro vezes superior à constatada na testemunha, a diferença em relação a esta não foi significativa (Tabela 6 ).

A partir do $21^{\circ} \mathrm{dia}$, os extratos de folhas de T. pallens e de ramos de $T$. pallida se igualaram, isolando-se como os melhores tratamentos, com mortalidades, respectivamente, de 70,5 e $65,1 \%$ no $21^{\circ}$ dia; 93,0 e $92,8 \%$ no $28^{\circ}$ dia e 95,4 e $96,4 \%$ ao final da fase larval (Tabela 6 ).

$\mathrm{Em}$ relação aos demais tratamentos, a eficiência tanto no $21^{\circ}$ quanto no $28^{\circ}$ dia, variou pouco em relação à avaliação anterior. Nesses dois períodos, além desses dois tratamentos mais eficientes (folhas de T. pallens e ramos de $T$. pallida), apenas o extrato de folhas de $T$. catigua superou a testemunha com 29,5 e $35,6 \%$ de mortalidade, aos 21 e 28 dias, respectivamente. A mortalidade causada pelas folhas de $T$. catigua, entretanto, não diferiu significativamente dos valores observados nos demais tratamentos, com exceção da testemunha ( 9,6 e 13,9\%, aos 21 e 28 dias, respectivamente) e de ramos de $T$. elegans aos 21 dias $(9,5 \%)$ (Tabela 6$)$.

Nestes dois períodos de avaliação, mesmo tratamentos aparentemente eficientes como ramos de $T$. catigua, $T$. claussenii e $T$. pallens e folhas de $T$. pallida, $T$. casaretti e $T$. claussenii, nos quais a mortalidade foi aproximadamente duas vezes maior que a constatada nas respectivas testemunhas, não diferiram significativamente destas (Tabela 6).

Ao final da fase larval, além dos extratos de folhas de $T$. pallens e ramos de $T$. pallida que foram os melhores tratamentos, outros quatro extratos (folhas de $T$. pallida, $T$. catigua e $T$. casaretti e ramos de $T$. claussenii) também apresentaram ação inseticida já que as mortalidades provocadas pelos mesmos $(45,4,40,8 ; 40,7$ e $39,8 \%$, respectivamente) também foram significativamente maiores que na testemunha $(16,9 \%)$. Para os demais tratamentos nos quais a mortalidade variou de 20,9 a $36,8 \%$, não houve diferença em relação à testemunha (Tabela 6). 
Tabela 6. Mortalidade de lagartas de Spodoptera frugiperda alimentadas com folhas de milho tratadas com extratos aquosos, a $1 \%$, de ramos $e$ folhas de Trichilia spp.

\begin{tabular}{|c|c|c|c|c|c|}
\hline \multirow[b]{2}{*}{ Tratamentos } & \multicolumn{5}{|c|}{ Mortalidade larval $(\%)^{1}$} \\
\hline & $7^{\circ} \mathrm{dia}$ & $14^{\circ} \mathrm{dia}$ & $21^{\circ} \mathrm{dia}$ & $28^{\circ} \mathrm{dia}$ & $\begin{array}{c}\text { Fase } \\
\text { completa }\end{array}$ \\
\hline Testemunha & $2,6 \mathrm{c}$ & $4,2 \mathrm{~d}$ & $9,6 \mathrm{c}$ & $13,9 \mathrm{c}$ & $16,9 \mathrm{~d}$ \\
\hline T. casaretti & $7,5 \mathrm{bc}$ & $12,7 \mathrm{~cd}$ & $14,1 \mathrm{bc}$ & $18,2 \mathrm{bc}$ & $20,9 \mathrm{~cd}$ \\
\hline T. catigua & $10,3 \mathrm{bc}$ & $17,2 \mathrm{bcd}$ & $25,9 \mathrm{bc}$ & $33,7 \mathrm{bc}$ & $36,8 \mathrm{bcd}$ \\
\hline 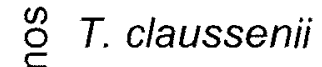 & $5,8 \mathrm{bc}$ & $13,8 \mathrm{~cd}$ & $17,3 \mathrm{bc}$ & $27,2 \mathrm{bc}$ & $39,8 b c$ \\
\hline$\underset{\mathbb{X}}{\simeq} T$. elegans & $4,2 \mathrm{c}$ & $4,2 \mathrm{~d}$ & $9,5 \mathrm{c}$ & $23,5 \mathrm{bc}$ & $31,2 \mathrm{bcd}$ \\
\hline T. pallens & $17,2 \mathrm{~b}$ & $18,5 \mathrm{bcd}$ & $22,4 \mathrm{bc}$ & $27,2 \mathrm{bc}$ & $30,9 \mathrm{bcd}$ \\
\hline T. pallida & $9,8 \mathrm{bc}$ & $34,1 b$ & 65,1 a & 92,8 a & 96,4 a \\
\hline \multirow{6}{*}{ 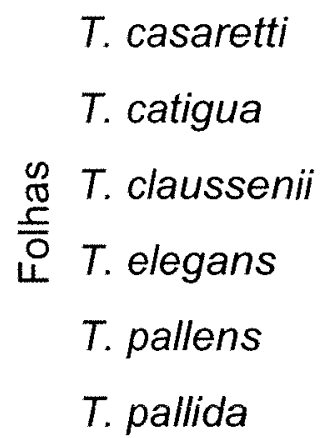 } & 9,8 bc & $13,6 \mathrm{~cd}$ & $21,8 \mathrm{bc}$ & $29,8 \mathrm{bc}$ & 40,7 bc \\
\hline & $12,9 \mathrm{bc}$ & $24,9 \mathrm{bc}$ & $29,5 b$ & $35,6 \mathrm{~b}$ & $40,8 \mathrm{bc}$ \\
\hline & $11,0 \mathrm{bc}$ & $12,2 \mathrm{~cd}$ & $22,7 \mathrm{bc}$ & 27,9 bc & $29,2 \mathrm{bcd}$ \\
\hline & $5,3 \mathrm{bc}$ & $9,3 \mathrm{~cd}$ & $12,1 \mathrm{bc}$ & $20,0 \mathrm{bc}$ & 27,2 bcd \\
\hline & 39,4 a & 51,6 a & $70,5 \mathrm{a}$ & 93,0 a & 95,4 a \\
\hline & $6,7 \mathrm{bc}$ & $17,7 \mathrm{bcd}$ & $25,3 \mathrm{bc}$ & $31,5 \mathrm{bc}$ & $45,4 \mathrm{~b}$ \\
\hline
\end{tabular}

${ }^{1}$ Médias seguidas pela mesma letra não diferem entre si pelo teste de Duncan a $5 \%$ de probabilidade de erro.

Com exceção de $T$. elegans, todas a demais espécies apresentaram ação inseticida sobre lagartas de $S$. frugiperda em pelo menos uma das estruturas testadas (Tabela 6). A não eficiência dos extratos aquosos tanto de folhas quanto de ramos de $T$. elegans sobre esta praga já havia sido constatada por Rodríguez (1995) e Rodríguez \& Vendramim (1996), quando os referidos extratos foram adicionados à dieta artificial e oferecidos às lagartas.

Em relação ao peso de lagartas no $8^{\circ}$ dia (Tabela 7 ), o extrato de folhas de T. pallens foi o melhor tratamento, seguido pelos extratos de ramos de 
T. pallida, de folhas de $T$. casaretti e $T$. pallida nos quais os pesos $(6,0 ; 9,1$; 13,1 e 18,2mg, respectivamente) foram significativamente inferiores ao registrado na testemunha $(37,9 \mathrm{mg})$. Os valores registrados nestes tratamentos (com exceção de folhas de T. pallida) também diferiram significativamente dos constatados nos demais tratamentos, nos quais os valores (variáveis entre 23,4 e $38,2 \mathrm{mg}$ ), não diferiram do verificado na testemunha (Tabela 7).

No $14^{\circ} \mathrm{dia}$, os únicos tratamentos em que o peso larval foi significativamente inferior ao observado na testemunha $(317,3 \mathrm{mg})$ foram os ramos de $T$. pallida e folhas de $T$. pallens, que se destacaram como os mais eficientes (com pesos larvais de 41,3 e 46,4mg, respectivamente) e folhas de $T$. casaretti e $T$, pallida (157,2 e 204,0mg, respectivamente). Os demais tratamentos não diferiram entre si (Tabela 7).

Os efeitos causados sobre a duração da fase larval foram bastante semelhantes aos verificados para peso larval no $14^{\circ}$ dia. Assim, os mesmos quatro tratamentos (folhas de $T$. pallens, $T$. casaretti e $T$. pallida e ramos de $T$. pallida) que causaram a maior redução no peso de lagartas, também causaram significativo alongamento na fase larval $(26,0 ; 25,7 ; 24,1$ e 25,5 dias, respectivamente) em relação ao valor verificado na testemunha $(20,6$ dias) (Tabela 7). O fato de a duração da fase larval e o peso de lagartas no $14^{\circ}$ dia terem apresentado as mesmas tendências ocorre freqüentemente nos estudos de biologia de insetos já que o menor peso apresentado pelas lagartas num determinado estádio de desenvolvimento indica que elas estão atrasadas em seu desenvolvimento, sendo portanto esperado que elas demorem mais tempo para atingir a fase pupal.

Torrecillas (1997) também constatou redução significativa da viabilidade larval e aumento dessa fase com a utilização de extratos aquosos de ramos de $T$. pallida a $1 \%$. 
Tabela 7. Peso ao $8^{\circ}$ e $14^{\circ}$ dia e duração da fase larval de Spodoptera frugiperda alimentada com folhas de milho tratadas com extratos aquosos, a 1\%, de ramos e folhas de Trichilia spp.

\begin{tabular}{|c|c|c|c|}
\hline \multirow{2}{*}{ Tratamentos } & \multicolumn{2}{|c|}{ Peso larval $(\mathrm{mg})^{1}$} & \multirow{2}{*}{ Fase larval (dias) } \\
\hline & $8^{\circ} \mathrm{dia}$ & $14^{\circ} \mathrm{dia}$ & \\
\hline Testemunha & 37,9 a & 317,3 a & $20,6 \mathrm{c}$ \\
\hline T. casaretti & 31,4 a & 311,5 a & $20,5 \mathrm{c}$ \\
\hline T. catigua & 38,1 a & 293,2 a & $21,6 \mathrm{bc}$ \\
\hline$\stackrel{\varrho}{\varrho} T$. claussenii & 38,2 a & 317,4 a & $20,0 \mathrm{c}$ \\
\hline$\stackrel{\bar{\pi}}{\not{D}} T$. elegans & 32,3 a & 320,2 a & $20,3 \mathrm{c}$ \\
\hline T. pallens & $24,0 a b$ & 308,5 a & $21,6 \mathrm{bc}$ \\
\hline T. pallida & $9,1 \mathrm{~d}$ & $41,3 \mathrm{c}$ & 25,5 a \\
\hline \multirow{6}{*}{ 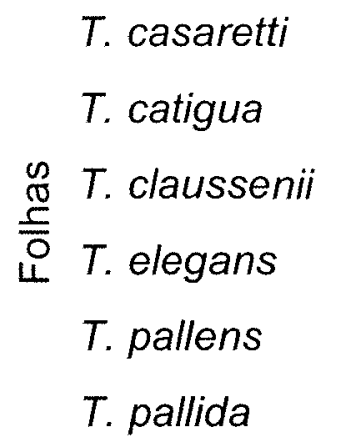 } & $13,1 \mathrm{~cd}$ & $157,2 b$ & 25,7 a \\
\hline & $23,4 a b$ & 300,7 a & $21,6 \mathrm{bc}$ \\
\hline & $27,1 a b$ & 327,6 a & $21,1 \mathrm{c}$ \\
\hline & 28,6 a & 283,4 a & $21,2 \mathrm{c}$ \\
\hline & $6,0 \mathrm{e}$ & $46,4 \mathrm{c}$ & 26,0 a \\
\hline & $18,2 \mathrm{bc}$ & $204,0 \mathrm{~b}$ & $24,1 a b$ \\
\hline
\end{tabular}

${ }^{1}$ Médias seguidas pela mesma letra não diferem entre si pelo teste de Duncan a $5 \%$ de probabilidade de erro.

A constatação de que os ramos de $T$. pallida, a partir do $14^{\circ}$ dia, afetaram não apenas a sobrevivência, mas também o peso e a duração da fase larval pode estar associado à presença de compostos que interferem na metamorfose, não apenas causando a mortalidade como dificultando o desenvolvimento das lagartas sobreviventes. Neste tratamento, constatou-se, em algumas lagartas, retenção da exúvia entre mudas e muda incompleta para a fase de pupa, fenômeno que já tinha sido observado, em relação a essa praga, por Rodríguez (1995), com a utilização de extratos aquosos em dieta e 
por Roel (1998), com a utilização de extratos metanólicos aplicados em folhas de milho.

A inibição do crescimento de $S$. frugiperda devido à utilização de extratos vegetais já tinha sido constatada por McMillian et al. (1969) que relataram o alongamento da fase larval em dieta artificial contendo extrato clorofórmico de folhas de Melia azedarach. Mikolajczak et al. (1988), utilizando extrato hexânico de sementes da meliácea Carapa procera, também verificaram inibição da alimentação de lagartas, quando os extratos eram aplicados sobre discos de feijoeiro, em testes com chance de escolha.

A inibição alimentar possivelmente seja a explicação para a baixa mortalidade de lagartas nos tratamentos com extratos de folhas de $T$. casaretti e T. pallida, até o $28^{\circ}$ dia de avaliação, embora estes extratos tenham afetado a sobrevivência ao final da fase, reduzido o peso larval e alongado esta fase em comparação às criadas na testemunha (Tabelas 6 e 7). A inibição alimentar causada por extrato de folhas de $T$. casaretti sobre lagartas de $S$. frugiperda foi constatada por Rodríguez \& Vendramim (1996); entretanto, com folhas de $T$. pallida, os mesmos autores verificaram índices de mortalidade mais acentuados, mas não constataram inibição alimentar. Estes autores também observaram inibição alimentar em dietas contendo extrato de ramos de $T$. catigua, fato este não constatado no presente trabalho (Tabelas 6 e 7), onde, com folhas desta espécie, foi verificado efeito na sobrevivência larval, o que não tinha sido observado por Rodríguez \& Vendramim (1997).

Rodríguez \& Vendramim $(1996,1997)$ não verificaram efeito dos extratos de folhas de $T$. claussenii e ramos de $T$. casaretti sobre a fase larval de S. frugiperda, corroborando os dados obtidos nesse trabalho (Tabelas 6 e 7). Dados divergentes em relação a esses autores, entretanto, foram observados com ramos de $T$. claussenii. Assim, enquanto tais autores constataram que este extrato alongou a fase larval, mas não afetou a viabilidade, na presente pesquisa ocorreu apenas redução da viabilidade larval (Tabelas 6 e 7). As variações podem ser explicadas pela metodologia utilizada, já que os referidos 
autores incorporaram os extratos em dieta artificial, enquanto que, neste trabalho, os mesmos foram impregnados em folhas de milho oferecidas às lagartas.

Embora os ramos de $T$. pallens e $T$. pallida tenham apresentado ação inseticida similar, quando utilizados extratos aquosos a $5 \%$ (Tabelas $3 \mathrm{e}$ 4), a eficiência de $T$. pallens não se repetiu na concentração de 1\% (Tabela 6), inclusive tendo efeito aparentemente menor que o causado por folhas de $T$. pallida cuja atividade inseticida a $5 \%$ havia sido pouco expressiva. A atividade inseticida de $T$. pallida no início da fase larval foi inferior à de ramos de $T$. pallens, porém, a partir do $7^{\circ}$ dia, a ação de seus extratos se intensificou, chegando os ramos a provocar mortalidade semelhante à observada em folhas de T. pallens (Figura 3 e Tabela 6).

\subsubsection{Fase pupal}

Os valores de peso de pupas para os tratamentos cujas lagartas foram alimentadas com extratos aquosos de ramos de T. pallida e folhas de $T$. pallens não foram utilizados para fins de análise, devido ao pequeno número de indivíduos (2 e 4 indivíduos, respectivamente). O maior efeito sobre este parâmetro foi constatado no tratamento folhas de $T$. pallida, cujo valor $(168,1 \mathrm{mg})$ diferiu significativamente de todos os outros tratamentos com exceção de folhas de $T$. casaretti $(175,3 \mathrm{mg})$. Além destes tratamentos, também ramos de $T$. pallens $(193,5 \mathrm{mg})$ e folhas de $T$. elegans $(208,4 \mathrm{mg})$ reduziram o peso de pupas em relação à testemunha $(251,1 \mathrm{mg})$, embora não tenham apresentado diferença significativa em relação aos demais tratamentos (Tabela 8).

Embora a duração da fase de pupa tenha variado entre 11,5 e 12,7 dias, não houve diferença significativa entre as médias (Tabela 8). Estes resultados estão de acordo com os obtidos por Rodríguez \& Vendramim (1996, 1997) que, trabalhando com cinco das seis espécies de Trichilia avaliadas na 
presente pesquisa, também não constataram efeito negativo dos extratos sobre a duração da fase pupal de $S$. frugiperda.

Os extratos aquosos de ramos de T. pallida e folhas de $T$. pallens causaram mortalidade total das pupas, destacando-se dos demais (Tabela 8), como também já tinha sido verificado em relação aos diversos parâmetros da fase larval. Dentre os demais tratamentos, o único que também superou a testemunha foi o extrato de folhas de $T$. casaretti que causou $54,6 \%$ de mortalidade. Por outro lado, embora em folhas de T. pallida, a mortalidade pupal $(31,5 \%)$ tenha superado aquela constatada em folhas de $T$. claussenii $(8,8 \%)$, ambas não diferiram da testemunha $(16,2 \%)$ (Tabela 8$)$.

Embora no presente trabalho não tenha sido constatado efeito dos extratos de folhas e ramos de $T$. catigua sobre a fase de pupa (Tabela 8), Rodríguez \& Vendramim (1996), avaliando os mesmos parâmetros, verificaram que o extrato de ramos dessa espécie reduziu o peso de pupas. O contrário ocorreu com $T$. elegans, cujo extrato de folhas reduziu o peso de pupas (Tabela 8) enquanto que no trabalho de Rodríguez \& Vendramim (1996), esta espécie não causou efeito sobre a fase pupal. Além das duas estruturas vegetais que causaram mortalidade total das pupas (ramos de $T$. pallida e folhas de $T$. pallens), as folhas de $T$. casaretti também se destacaram quanto ao efeito sobre a fase pupal reduzindo a viabilidade e o peso, sendo que os efeitos desta estrutura sobre o peso de pupas já tinham sido constatados por Rodríguez \& Vendramim (1996). 
Tabela 8. Peso, duração e mortalidade na fase pupal de Spodoptera frugiperda alimentada na fase larval com folhas de milho tratadas com extratos aquosos, a 1\%, de ramos e folhas de Trichilia spp.

\begin{tabular}{|c|c|c|c|}
\hline Tratamentos & $\begin{array}{l}\text { Peso } \\
(\mathrm{mg})^{1}\end{array}$ & $\begin{array}{l}\text { Duração da } \\
\text { fase (dias) }\end{array}$ & $\begin{array}{c}\text { Mortalidade } \\
(\%)^{1}\end{array}$ \\
\hline Testemunha & 251,1 a & 11,9 & $16,2 \mathrm{~cd}$ \\
\hline$T$. casaretti & $224,3 a b$ & 12,3 & $11,1 \mathrm{~cd}$ \\
\hline T. catigua & $218,0 a b$ & 11,8 & $13,9 \mathrm{~cd}$ \\
\hline$\cong$ T. claussenii & $219,9 a b$ & 11,7 & $21,6 \mathrm{~cd}$ \\
\hline 离 T. elegans & $218,3 a b$ & 11,9 & $13,5 \mathrm{~cd}$ \\
\hline T. pallens & $193,5 \mathrm{bc}$ & 11,9 & $16,8 \mathrm{~cd}$ \\
\hline T. pallida & -- & -- & $100,0 a$ \\
\hline T. casaretti & $175,3 \mathrm{~cd}$ & 11,5 & $54,6 \mathrm{~b}$ \\
\hline T. catigua & $214,0 a b$ & 12,3 & $25,2 \mathrm{~cd}$ \\
\hline$\stackrel{\mathbb{\pi}}{\approx}$ T. claussenii & $223,3 a b$ & 12,1 & $8,8 \mathrm{~d}$ \\
\hline 오 $T$. elegans & $208,4 b$ & 12,7 & $29,4 \mathrm{~cd}$ \\
\hline T. pallens & - & -- & $100,0 a$ \\
\hline T. pallida & $168,1 \mathrm{~d}$ & 12,0 & $31,5 \mathrm{c}$ \\
\hline
\end{tabular}

${ }^{1}$ Médias seguidas pela mesma letra não diferem entre si pelo teste de Duncan a $5 \%$ de probabilidade de erro.

${ }^{2}$ Médias não diferem entre si pelo teste $\mathrm{F}$ a $5 \%$ de probabilidade de erro.

\subsubsection{Adultos defeituosos}

Alguns dos extratos aquosos de ramos e folhas de Trichilia aplicados às folhas de milho oferecidas às lagartas, além do efeito sobre as fases de larva e pupa, também afetaram a formação dos adultos. O principal defeito constatado nos adultos foi a má formação de asas (presentes em todos 
os indivíduos deformados) e antenas. O maior número de adultos defeituosos ocorreu no tratamento com folhas de $T$. pallida, com $24,5 \%$. Nos tratamentos à base de ramos de $T$. casaretti e $T$. pallens e de folhas de $T$. elegans e $T$. catigua, os defeitos foram verificados em mais de $10 \%$ dos adultos, enquanto que na testemunha, nos ramos de $T$. claussenii e de $T$. elegans, os indivíduos defeituosos corresponderam a menos de $5 \%$ do total (Figura 4).

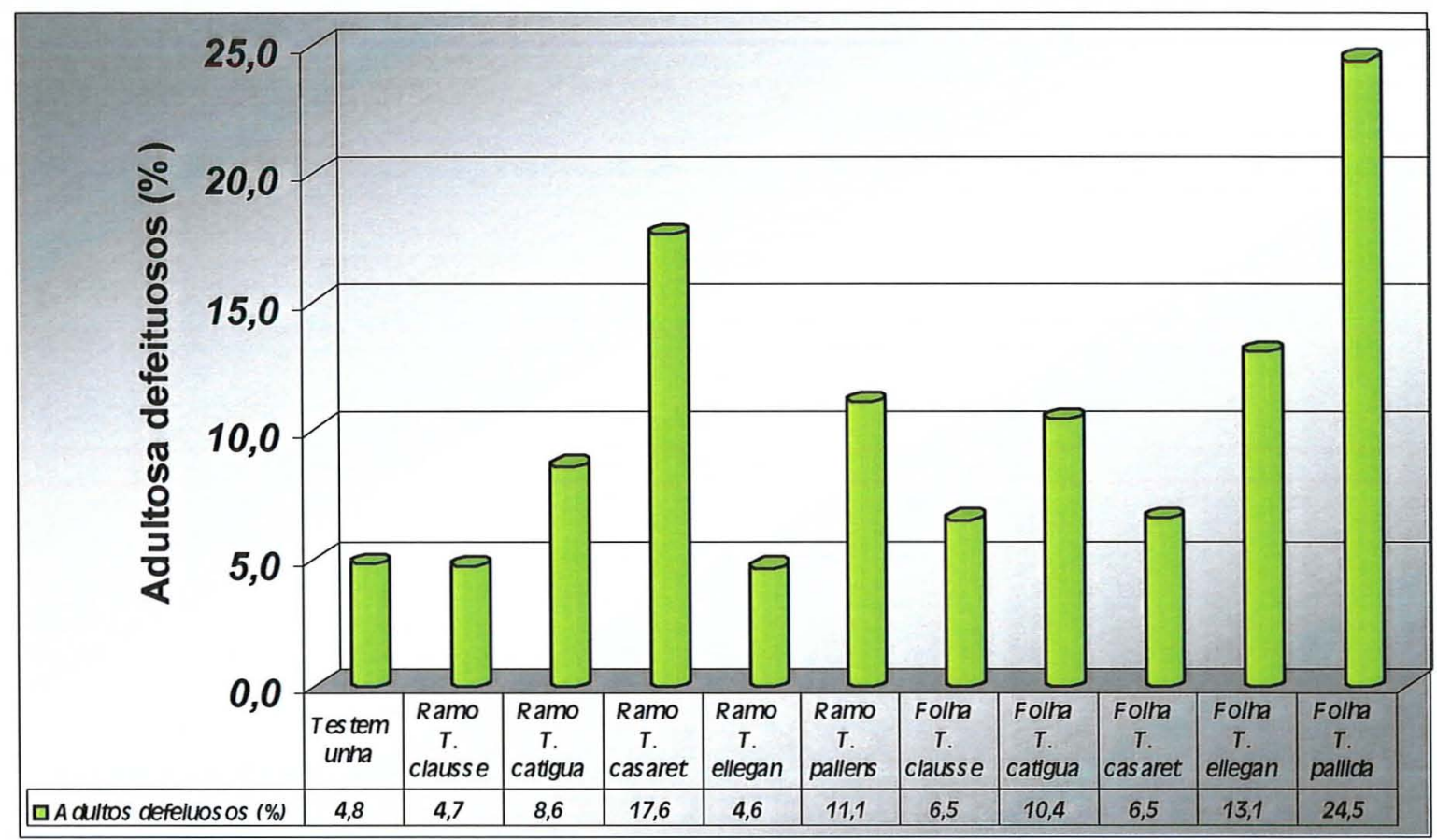

Figura 4 - Adultos defeituosos de Spodoptera frugiperda provenientes de lagartas alimentadas com folhas de milho tratadas com extratos aquosos, a $1 \%$, de ramos e folhas de Trichilia spp.

De modo geral, considerando-se os parâmetros avaliados nos diversos experimentos (Tabelas 2 a 8 ), verifica-se que dentre as espécies de Trichilia testadas, a maior eficiência foi constatada com folhas de T. pallens e ramos de $T$. pallida que afetaram todos os parâmetros avaliados, e folhas de $T$. casaretti e $T$. pallida que afetaram a maioria dos parâmetros. 
O extrato aquoso de folhas de $T$. pallens, cuja eficiência foi semelhante à constatada com extrato de sementes de Azadirachta indica pode ser considerado bastante promissor, pois esta é considerada atualmente a espécie vegetal com maior atividade inseticida com efeitos comprovados sobre mais de 400 espécies de insetos (Govindachari, 1992; Koul et al., 1990; Martinez, 2002; Mordue (Luntz) \& Blackwell, 1993; Rodríguez, 1995; Schmutterer, 1988,1990; Warthen Jr., 1989).

A ação de $T$. pallida, caracterizada principalmente pelo efeito sobre o desenvolvimento larval, pode estar associada, como mencionado anteriormente (item 4.1.2.1), a alterações hormonais que interferem no processo de muda. Este tipo de alteração hormonal, afetando a metamorfose de insetos, já foi observado com extratos de A. indica (Govindachari, 1992; Klocke, 1987 e Mordue (Luntz) \& Blackwell, 1993) e embora isso ainda não tenha sido comprovado com os extratos de $T$. pallida, existem constatações de interrupção no processo de ecdise, ficando parte da exúvia retida nos últimos segmentos abdominais, bem como, ecdise incompleta para a fase de pupa (Rodríguez, 1995; Roel, 1998 e Torrecillas, 1997).

Dentre as fases de desenvolvimento de $S$. frugiperda, a fase larval foi relativamente mais suscetivel à ação dos extratos (itens 4.1.2.1 e 4.1.2.2), o que concorda com as observações de Torrecillas (1997) para T. pallida.

Ao contrário do que havia sido constatado com T. pallida por Torrecillas (1997) e com T. catigua e T. claussenii por Rodríguez \& Vendramim (1996, 1997), as folhas das várias espécies de Trichilia avaliadas neste trabalho causaram maior efeito sobre o desenvolvimento da praga que os ramos, sendo que apenas as de $T$. claussenii foram ineficientes. Já para $T$. casaretti, o extrato de folhas foi mais eficiente que o de ramos (Rodríguez \& Vendramim, 1996). 


\subsubsection{Preferência de lagartas por folhas de milho tratadas e não tratadas com extratos de Trichilia spp.}

Dentre os 12 tratamentos testados, apenas os extratos de folhas e ramos de $T$. catigua e de folhas de $T$. claussenii apresentaram efeito deterrente sobre a alimentação das lagartas de $S$. frugiperda com índices de consumo de 0,$70 ; 0,77$ e 0,72 , respectivamente (Tabela 9 ).

Os demais tratamentos não afetaram o consumo larval, com exceção do extrato de ramos de $T$. elegans que apresentou efeito fagoestimulante (Tabela 9).

Testando ramos e folhas das mesmas espécies de Trichilia avaliadas neste trabalho (com exceção de T. pallens), Rodríguez (1995) constatou efeito deterrente em ramos de $T$. catigua sobre lagartas de $4^{\circ}$ instar de $S$. frugiperda, enquanto que as estruturas das demais espécies não afetaram o consumo de alimento.

O efeito deterrente alimentar de meliáceas sobre $S$. frugiperda é bastante comum, tendo sido constatado em sementes de nim, associado à presença do limonóide azadiractina (Raffa, 1987 e Warthen Jr., 1989). Mikolajczak \& Reed (1987) constataram ação deterrente em extratos etanólicos e hexânicos de meliáceas, incluindo algumas espécies do gênero Trichilia, porém, nenhuma delas pesquisadas neste trabalho.

Considerando os diversos testes realizados, foram selecionados os extratos de folhas de $T$. pallens, de ramos de $T$. pallida e T. pallens, como os tratamentos com maior potencial e, portanto, utilizados para o teste de campo. 
Tabela 9. Indice de preferência de lagartas de $4^{\circ}$ ínstar de Spodoptera frugiperda alimentada com folhas de milho tratadas com extratos aquosos, a $1 \%$, de ramos e folhas de Trichilia spp.

\begin{tabular}{|c|c|c|c|}
\hline \multicolumn{2}{|c|}{ Tratamentos } & $I C \pm E . P .{ }^{1}$ & Classificação $^{2}$ \\
\hline \multirow{6}{*}{ 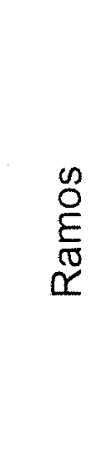 } & T. casaretti & $0,93 \pm 0,146$ & $N$ \\
\hline & T. catigua & $0,77 \pm 0,133$ & D \\
\hline & T. claussenii & $1,12 \pm 0,155$ & $N$ \\
\hline & T. elegans & $1,23 \pm 0,113$ & $E$ \\
\hline & T. pallens & $1,01 \pm 0,152$ & $N$ \\
\hline & T. pallida & $1,05 \pm 0,142$ & $N$ \\
\hline \multirow{6}{*}{$\begin{array}{l}\mathscr{D} \\
\stackrel{D}{ \pm} \\
\overline{\bar{O}} \\
\stackrel{1}{1}\end{array}$} & T. casaretti & $0,96 \pm 0,171$ & $N$ \\
\hline & T. catigua & $0,70 \pm 0,145$ & D \\
\hline & T. claussenii & $0,72 \pm 0,111$ & $D$ \\
\hline & T. elegans & $1,05 \pm 0,140$ & $N$ \\
\hline & T. pallens & $1,15 \pm 0,153$ & $N$ \\
\hline & T. pallida & $1,01 \pm 0,169$ & $N$ \\
\hline
\end{tabular}

1 Indice de preferência \pm erro padrão da média.

${ }^{2}$ Classificação: $E$ = estimulante; $D=$ deterrente; $N=$ neutro.

\subsection{Bioensaio de campo}

A infestação artificial nas plantas de milho realizada neste ensaio foi eficiente, permitindo boa homogeneidade na distribuição das lagartas nas diversas parcelas, o que pode ser confirmado pelas notas de dano bastante similares antes da aplicação dos tratamentos (Tabela 10).

Os danos causados ao milho tanto na testemunha quanto nos tratamentos com extratos aquosos de ramos de $T$. pallida, ramos e folhas de $T$. pallens e óleo de nim, aumentaram ao longo das avaliações (Tabela 10). No 
tratamento com extratos aquosos de sementes de nim, as notas de dano na primeira avaliação não diferiram das obtidas na segunda e terceira avaliações embora nesta última tenha ocorrido valor maior em relação à avaliação precedente. O tratamento químico foi o único que reduziu os danos durante todo o periodo de avaliação.

Em relação à eficiência dos tratamentos, foi constatada redução do dano na primeira semana após a aplicação dos tratamentos apenas com lufenuron. Na terceira (última) avaliação, este tratamento também apresentou a maior eficiência diferindo significativamente do extrato de nim, que foi o segundo tratamento mais eficiente. $O$ extrato de folhas de $T$. pallens foi o único entre os demais tratamentos que também causou significativa redução no dano em relação à testemunha (Tabela 10 ).

O fato de o tratamento com óleo de nim não ter provocado redução nos danos durante o período de avaliação, pode ter sido devido à quantidade insuficiente de emulsificante utilizada no preparo da calda para a primeira pulverização, o que pode ter prejudicado a sua atividade inseticida.

Trabalhos avaliando o efeito de extratos vegetais no campo não são muito comuns. Villar et al. (1990) mostraram que extratos aquosos de $T$. havanensis e T. americana, aplicados três vezes por semana no campo, reduziram o dano de $S$. frugiperda, levando a um aumento de mais de um tonelada de milho por hectare em relação à testemunha (água + sabão). A eficiência de produtos à base de sementes de nim em pó (Cubanim-t) e óleo de nim (Oleonim $50 \mathrm{CE}$ e Oleonim $80 \mathrm{CE}$ ) aplicados em milho no campo para controle de $S$. frugiperda foi comprovada por Pérez et al. (1997). Os autores mostraram que ambos os produtos foram semelhantes na capacidade de reduzir a população de lagartas no campo até a segunda aplicação (8 dias entre aplicações) em comparação à lambdacialotrina (Karate ${ }^{\circledR} 2,5 \mathrm{CE}$ ). 
Tabela 10. Nota de dano ${ }^{1}$ causado por lagartas de Spodoptera frugiperda em plantas de milho, cultivadas em campo e tratadas com extratos aquosos de meliáceas, óleo de nim e lufenuron. Piracicaba, SP, 2002.

\begin{tabular}{lccc}
\hline \multirow{2}{*}{ Tratamentos } & \multicolumn{4}{c}{ Datas de avaliação $^{2}$} \\
\cline { 2 - 4 } & $24 / 09 / 02$ & $01 / 10 / 02$ & $08 / 10 / 02$ \\
\hline Testemunha & $2,72 \mathrm{Aa}$ & $3,08 \mathrm{Ba}$ & $3,91 \mathrm{Ca}$ \\
Folhas de T. pallens $(6,7 \%)$ & $2,48 \mathrm{Aa}$ & $3,01 \mathrm{Ba}$ & $3,49 \mathrm{Cb}$ \\
Ramos de T. pallens (6,7\%) & $2,50 \mathrm{Aa}$ & $3,01 \mathrm{Ba}$ & $3,59 \mathrm{Cab}$ \\
Ramos de T. pallida (6,7\%) & $2,49 \mathrm{Aa}$ & $2,98 \mathrm{Ba}$ & $3,58 \mathrm{Cab}$ \\
Sementes de nim (6,7\%) & $2,55 \mathrm{ABa}$ & $2,46 \mathrm{Ab}$ & $2,82 \mathrm{Bc}$ \\
Óleo de nim (0,5\%) & $2,63 \mathrm{Aa}$ & $3,05 \mathrm{Ba}$ & $3,86 \mathrm{Ca}$ \\
Lufenuron (Match® CE) & $2,65 \mathrm{Ca}$ & $2,36 \mathrm{Bb}$ & $2,03 \mathrm{Ad}$ \\
\hline
\end{tabular}

Segundo escala de notas de Cruz et al. (1983).

${ }^{2}$ Médias seguidas pela mesma letra maiúsculas nas linhas e minúsculas nas colunas, não diferem entre si pelo teste de Duncan a $5 \%$ de probabilidade de erro.

Embora a redução de dano observada com extrato aquoso a $6,7 \%$ de folhas de $T$. pallens tenha sido inferior às constatadas para os tratamentos químico (lufenuron) e extrato aquoso de sementes de nim, é possível que o referido extrato tenha a sua eficiência aumentada pela adição de adjuvantes (antioxidantes e/ou estabilizantes) o que evitaria uma degradação prematura dos compostos que apresentaram efeito sobre a praga nos testes em laboratório. 


\section{CONCLUSÕES}

- Para as seis espécies de Trichilia (T. casaretti, T. catigua, T. claussenii, T. elegans, $T$. pallens e $T$. pallida), avaliadas na forma de extrato aquoso, ao menos uma das suas estruturas (ramos e/ou folhas) afeta $o$ desenvolvimento de $S$. frugiperda.

- À concentração de $5 \%$, o extrato de folhas de T. pallens causa $100 \%$ de mortalidade larval até o $5^{\circ}$ dia, efeito semelhante ao causado pelo extrato aquoso de sementes de Azadirachta indica (nim).

- Extratos a $5 \%$ de ramos e frutos (verdes e maduros) de T. pallens, e de ramos e folhas de $T$. pallida, embora menos eficientes que os extratos de folhas de $T$. pallens e de sementes de nim, também reduzem a sobrevivência e o peso larval dessa praga.

- Extratos a $5 \%$ de ramos de $T$. pallens e $T$. pallida são mais eficientes que o de folhas de T. pallida.

- O extrato de frutos de T. pallens é menos eficiente que os extratos de folhas e ramos dessa espécie vegetal.

- A concentração de $1 \%$, os extratos de ramos de T. pallida e de folhas de $T$. pallens são os mais eficientes, dentre as seis espécies de Trichilia testadas, matando mais de $95 \%$ das lagartas. 
- Extratos, a 1\%, de folhas de $T$. pallida e $T$. casaretti, afetam o desenvolvimento de $S$. frugiperda, reduzindo a sobrevivência e os pesos larval e pupal, e alongando a fase larval.

- A essa mesma concentração, extratos de ramos de T. claussenii e de folhas de $T$. catigua reduzem a sobrevivência larval, e extratos de ramos de $T$. pallens e de folhas de $T$. elegans reduzem o peso pupal.

- Extratos de folhas de T. claussenii e de ramos de T. catigua, T. casaretti e T. elegans, a $1 \%$, não afetam o desenvolvimento de S. frugiperda.

- Extratos de folhas de $T$. catigua e $T$. claussenii, e de ramos de $T$. catigua, a $1 \%$, inibem a alimentação de lagartas, enquanto que o extrato de ramos de T. elegans é fago-estimulante.

- Em condições de campo, os extratos, a 6,7\%, de folhas de T. pallens e de sementes de $A$. indica, embora menos eficientes que o inseticida sintético lufenuron, reduzem o dano das lagartas à cultura do milho. 


\section{REFERÊNCIAS BIBLIOGRÁFICAS}

ALI, A.; LUTTRELL, R.G.; SCHNEIDER, J.C. Effects of temperature and larval diet on development of the fall armyworm (Lepidoptera: Noctuidae) Annals of the Entomological Society of America, v.83, n.4, p.725-733, 1990.

AREANAS, C.; RODRIGUEZ-HAHN, L. Limonoids from Trichilia havanensis. Phytochemistry, v.29, n.9, p.2953-2956, 1990.

ÁVILA, C.J.; DEGRANDE, P.E.; GOMES, S.A. Insetos-pragas: reconhecimento, comportamento, danos e controle. In. EMBRAPA-CPAO. Milho: informações técnicas. Dourados, 1997. p.157-181. (EMBRAPA-CPAO. Circular Técnica, $5)$.

BAMBARKAR, S. Neem - A vast potential for agrochemicals. Pesticides, p.3640, Jan. 1990.

BIANCO, R. Pragas e seu controle. In. FUNDAÇÃO INSTITUTO AGRONÔMICO DO PARANÁ, A cultura do milho no Paraná. Londrina, 1991. p.185-221. (IAPAR. Circular, 29).

BRETT, C.H.; BASTIDA, R. Resistance of sweet corn varieties to the fall armyworm, Laphygma frugiperda. Journal of Economic Entomology, v.56, n.2, p.162-167, 1963. 
BURTON, R.L.; PERKINS, W.D. WSB, a new laboratory diet for the corn earworm and the fall armyworm. Journal of Economic Entomology, v.65, n.2, p.385-386, 1972.

BUTTERWORTH, J.H.; MORGAN, E.D. Investigation of the locust feeding inhibition of seeds of the neem tree, Azadirachta indica. Journal of Insect Physiology, v.17, p.969-977, 1971.

CARMEN R., M.; TOSCANO, R.A.; ARNASON, J. et al. Structure, conformation and absolute configuration of new antifeedant dolabellanes from Trichilia trifolia. Tetrahedron, v.56, p.5085-5091, 2000.

CARVALHO, A.O.R. Pragas e seu controle. In: FUNDAÇÃO INSTITUTO AGRONÔMICO DO PARANÁ, O milho no Paraná. Londrina, 1982. p.141148. (IAPAR. Circular, 68).

CARVALHO, R.P.L. Danos, flutuação populacional, controle e comportamento de Spodoptera frugiperda (J.E. Smith, 1797) e suscetibilidade de diferentes genótipos de milho em condições de campo. Piracicaba, 1970.170p. Tese (Doutorado) - Escola Superior de Agricultura "Luiz de Queiroz", Universidade de São Paulo.

CHAURET, D.C.; DURST, T.; AMASON, J.T. et al. Novel steroids from Trichilia hirta as identified by nanoprobe inadequate 2D-NMR spectroscopy. Tetrahedron Letters, v.37, n.44, p.7875-7878, 1996.

CORTEZ, D.A.G; VIEIRA, P.C.; FERNANDES, J.B. et al. Limonoids from Trichilia hirta. Phytochemistry, v.31, n.2, p.625-628, 1992. 
CORTEZ, D.A.G; FERNANDES, J.B.; VIEIRA, P.C. et al. Meliacin butenolides from Trichilia estipulata. Phytochemistry, v.49, n.8, p.2493-2496, 1998.

CORTEZ, D.A.G; FERNANDES, J.B.; VIEIRA, P.C. et al. A limonoid from Trichilia estipulata. Phytochemistry, v.55, p.711-713, 2000.

CROCOMO, W.B.; PARRA, J.R.P. Consumo e utilização de milho, trigo e sorgo por Spodoptera frugiperda (J.E. Smith, 1797) (Lepidoptera, Noctuidae). Revista Brasileira de Entomologia, v.29, n.2, p.225-260, 1985.

CRUZ, I. Impact of fall armyworm, Spodoptera frugiperda (Smith and Abbot, 1797), on grain yield in field corn. Lafayette, 1980. 162p. Dissertation (M.S.) - Purdue University.

CRUZ, I.; TURPIN, F.T. Efeito de Spodoptera frugiperda em diferentes estágios de crescimento da cultura de milho. Pesquisa Agropecuária Brasileira, v.17, n.3, p.355-359, 1982.

CRUZ, I. A lagarta-do-cartucho na cultura do milho. Sete Lagoas: Embrapa, 1995. 45p. (EMBRAPA-CNPMS, Circular Técnica, 21).

DREYER, M. Neem - Un promisorio insecticida natural para pequeños productores de vegetales de la Republica Dominicana. Republica Dominicana: GTZ, s.d. 1v.

FERRAZ, M.C.V.D. Determinação das exigências térmicas de Spodoptera frugiperda (J.E. Smith, 1797) (Lepidoptera, Noctuidae) em cultura de milho. Piracicaba, 1982. 81p. Tese (Mestrado) - Escola Superior de Agricultura "Luiz de Queiroz", Universidade de São Paulo. 
GARCEZ, F.R.; GARCEZ, W.S.; RODRIGUEZ, E.D. et al. Seco-protolimonoids from Trichilia elegans ssp. elegans. Phytochemistry, v.42, n.5, p.13991403, 1996,

GARCEZ, F.R.; GARCEZ, W.S.; TSUTSUMI, M.T. Limonoids from Trichilia elegans ssp. elegans. Phytochemistry, v.45, n.1, p.141-148, 1997.

GARCEZ, F.R.; GARCEZ, W.S.; ROQUE, N.F. et al. 7(beta)-oxygenated limonoids from Trichilia elegans ssp. elegans. Phytochemistry, v.55, p.733$740,2000$.

GASSEN, D. Pragas associadas à cultura do milho. Passo Fundo: Aldeia Norte, 1994, 92p.

GOVINDACHARI, T.R. Chemical and biological investigations on Azadirachta indica (the neem tree). Current Science. v.63, n.3, p.117-122, 1992.

GOVINDACHARI, T.R.; GOPALAKRISHNAN, G. 13,14-desepoxyazadirachtinA, a tetranortriterpenoid from Azadirachta indica. Phytochemistry, v.45, n.2, p.397-399, 1997.

GUNATILAKA, A.A.L.; BOLZANI, V.S.; DAGNE, E. et. al. Limonoids showing selective toxicity to DNA repair-deficient yeast and other constituents of Trichilia emetica. Journal of Natural Products, v.61, p.179-184, 1998.

HANTOS, S.M.; TRIPATHY, S.; ALIBHAI, N. et al. Synthesis of trichiliasterones A and B - 16-ketosteroids isolated from Trichilia hirta and Trichilia americana. Canadian Journal of Chemical, v.79, p. 1747-1753, 2001. 
HERNÁNDEZ X.,E.; INUZUNZA M.,F.R.; SOLANO S.,C.B. Intentos de control de plagas y enfermidades identificadas en la agricultura tradicional en México. Revista Chapingo, v.8, n.40, p.55-56, 1983.

INADA, A.; KONISHI, M.; HIROKO, M.; NAKANISHI, T. Structures of a new limonoid and a new triterpenoid derivative from pericarps of Trichilia connaroides. Journal of Natural Products. v.57, n.10, p.1446-1449, 1994.

JOLAD, S.D.; HOFFMANN, J.J.; COLE, J.R. Constituents of Trichilia hispida (Meliaceae). 2. A new triterpenoid, hispidone, and bourjotinolone A. Journal of Organic Chemistry, v.45, n.15, p.3132-3135, 1980.

KASTEN JUNIOR, P.; PRECETTI, A.A.C.M.; PARRA, J.R.P. Dados biológicos comparativos de Spodoptera frugiperda (J.E. Smith, 1797) em duas dietas artificiais e substrato natural. Revista de Agricultura, v.53, n.1/2, p.68-72, 1978.

KLOCKE, J.A. Natural plant compounds useful in insect control. In: WALLER, G.R.; (Ed.). Allelochemicals: role in agriculture and forestry. Washington: American Chemical Society, p.396-415, 1987. (American Chemical Society Symposium Series, 330).

KOGAN, M.; GOEDEN, R.D. The host-plant range of Lema trilineata daturaphila (Coleoptera: Chrysomelidae). Annals of the Entomological Society of America, v. 63, p.1175-1180, 1970.

KOUL, O.; ISMAN, M.B.; KETKAR, C.M. Properties and uses of neem, Azadicachta indica. Canadian Journal of Botanic, v.68, p.1-11, 1990. 
LEIDERMAN, L; SAUER, H.F.G. A lagarta dos milharais Laphygma frugiperda (Abbot e Smith, 1797). O Biológico, v.19, n.6, p.105-113, 1953.

MARTINEZ, S.S. (Ed.). O Nim - Azadirachta indica: natureza, usos múltiplos, produção. Londrina: Instituto Agronômico do Paraná, 2002. 142p.

MCMILLIAN, W.W.; BOWMAN, M.C.; BURTON, R.L.; STARKS, K.J.; WISEMAN, B.R. Extracts of chinaberry leaf as a feeding deterrent and growth retardant for larvae of the corn earworm and fall armyworm. Journal of Economic Entomology, v.62, n.3, p.708-710, 1969.

MELO, M.; SILVA, R.F.P. Influência de três cultivares de milho no desenvolvimento de Spodoptera frugiperda (J.E. Smith, 1797) (Lepidoptera, Noctuidae). Anais da Sociedade Entomológica do Brasil, v.16, n.1, p.3749, 1987.

MIKOLAJCZAK, K.L.; REED, D.K. Extractives of seeds of the Meliaceae: effects on Spodoptera frugiperda (J.E. Smith), Acalymma vittatum (F.), and Artemia salina Leach. Journal of Chemical Ecology, v.13, n.1, p.99-111, 1987.

MIKOLAJCZAK, K.L.; WEISLEDER, D.; PARKANYI, L. et al. A limonoid antifeedant from seed of Carapa procera. Journal of Natural Products, v.51, n.3, p.606-610, 1988.

MOOTOO, B.S.; RAMSEWAK, R. Tetranortriterpenoids from Ruagea glabra. Journal of Natural Products, v.59, p.544-547, 1996.

MOOTOO, B.S.; ALI, A.; MOTILAL, R. et al. Limonoids from Swietenia macrophylla and S. aubrevilleana. Journal of Natural Products, v.62, p.1514-1517, 1999. 
MORDUE (LUNTZ), A.J.; BLACKWELL, A. Azadirachtin: an update. Journal of Insect Physiology, v.39, n.11, p.903-924,1993.

MUSZA, L.L.; KILLAR, L.M.; SPEIGHT, P. et al. Minor limomoids from Trichilia rubra. Phytochemistry, v.39, n.3, p.621-624, 1995.

NAKANISHI, K. Recent studies on bioactive compounds from plants. Journal of Natural Products, v.45, n.1, p.15-26, 1982.

NAKATANI, M.; JAMES, J.C.; NAKANISHI, K. Isolation and structures of trichilins, antifeedants against the southern army worm. Journal of American Chemical Society, v.103, p.1228-1230, 1981.

OLUGBADE, T.A. Tetracyclic triterpenoids from Trichilia prieuriana leaves. Phytochemistry, v.30, n.2, p.698-700, 1991.

OLUGBADE, T.A.; ADESANYA, S.A. Prieurianoside, a protolimonoid glucoside from the leaves of Trichilia prieuriana. Phytochemistry, v.54, p.867-870, 2000.

ORTEGO, F.; LÓPEZ, J.O.; RUIZ, M. et al. Effects of toxic and deterrent terpenoids on digestive protease and detoxication enzyme activities of Colorado potato beetle larvae. Pesticide Biochemistry and Physiology, v.63, p.76-84, 1999.

PENNIGTON, I.D. Flora neotropica. New York: New York Botanical Garden, 1981. 470p. (monograph 28. Meliaceae). 
PÉREZ, G.; PADRÓN, R.; SOTO, R.; BERTSCH, F. Efecto de tres plaguicidas naturales derivados del nim sobre el combate de plagas en col y maiz en el campo, y en Vigna unguiculata en almacenamento. Agronomia Costarricense, v.21, n.2, p.259-266, 1997.

POWELL, R.G.; MIKOLAJCZAK, K.L.; ZILKOWSKI, B.W. Limonoid antifeedants from seed of Sandoricum koetijape. Journal of Natural Products, v.54, n.1, p.241-246, 1991.

PUPO, M.T.; VIEIRA, P.C.; FERNANDES, J.B. et al. A cycloartane triterpenoid and (omega)-phenyl alkanoic and alkenoic acids from Trichilia claussenii. Phytochemistry, v.42, n.3, p.795-798, 1996.

PUPO, M.T.; VIEIRA, P.C.; FERNANDES, J.B. et al. Androstane and pregnane 2(beta),19-hemiketal steroids from Trichilia claussenii. Phytochemistry, v.45, n.7, p.1495-1500, 1997.

PUPO, M.T.; VIEIRA, P.C.; FERNANDES, J.B. et al. y-Lactones from Trichilia claussenii. Phytochemistry, v.48, n.2, p.307-310, 1998.

RAFFA, K.F. Influence of host plant on deterrence by azadirachtin of feeding by fall armyworm larvae (Lepidoptera: Noctuidae). Journal of Economic Entomology, v.80, p.384-387, 1987.

RODRÍGUEZ H., C. Efeito de extratos aquosos de Meliaceae no desenvolvimento de Spodoptera frugiperda (J.E. Smith, 1797) (Lepidoptera: Noctuidae). Piracicaba, 1995. 100p. Tese (Doutorado) - Escola Superior de Agricultura "Luiz de Queiroz", Universidade de São Paulo. 
RODRÍGUEZ H., C.; VENDRAMIM, J.D. Toxicidad de extractos acuosos de Meliaceae en Spodoptera frugiperda (Lepidoptera: Noctuidae). Manejo Integrado de Plagas, v.42, p.14-22, 1996.

RODRÍGUEZ H., C.; VENDRAMIM, J.D. Avaliação da bioatividade de extratos aquosos de Meliaceae sobre Spodoptera frugiperda (J.E. Smith). Revista de Agricultura, v.72, n.3, p.305-318, 1997.

RODRÍGUEZ H., C.; VENDRAMIM, J.D. Uso de indices nutricionales para medir el efecto insectistatico de extractos de meliáceas sobre Spodoptera frugiperda. Manejo Integrado de Plagas, v.48, p.11-18, 1998.

RODRÍGUEZ-HAHN, L.; CÁRDENAS, J.; ARENAS,C. Trichavensin, a prieurianin derivative from Trichilia havanensis. Phytochemistry, v.43, n.2, p.457-459, 1996.

ROEL, A.R. Efeito de extratos aquosos de Trichilia pallida Swartz (Meliaceae) na sobrevivência e desenvolvimento de Spodoptera frugiperda (J.E. Smith, 1797) (Lepidoptera: Noctuidae). Piracicaba, 1998. 115p. Tese (Doutorado) Escola Superior de Agricultura "Luiz de Queiroz", Universidade de São Paulo.

ROEL, A.R.; VENDRAMIM, J. D. Desenvolvimento de Spodoptera frugiperda (J.E. Smith) em genótipos de milho tratados com extrato acetato de etila de Trichilia pallida (Swartz). Scientia Agricola, v.56, n.3, p.581-586, 1999.

ROEL, A.R.; VENDRAMIM, J. D.; FRIGHETTO, R.T.S. et al. Atividade tóxica de extratos orgânicos de Trichilia pallida Swartz (Meliaceae) sobre Spodoptera frugiperda (J.E. Smith). Anais da Sociedade Entomológica do Brasil, v.29, n.4, p.799-808, 2000a. 
ROEL, A.R.; VENDRAMIM, J. D.; FRIGHETTO, R.T.S. et al. Efeito do extrato acetato de etila de Trichilia pallida Swartz (Meliaceae) no desenvolvimento e sobrevivência da lagarta-do-cartucho. Bragantia, v.59, n.1, p.53-58, $2000 \mathrm{~b}$.

SCHMUTTERER, $H$. Potential of azadirachtin-containing pesticides for integrated pest control in developing and industrialized countries. Journal Insect Physiology, v.34, n.7, p.713-719, 1988.

SCHMUTTERER, $H$. Properties and potential of natural pesticides from the neem tree, Azadirachta indica. Annual Review of Entomology, v.35, p.271-297, 1990.

SILVEIRA, L.C; VENDRAMIM. J.D.; ROSSETTO, C.J. Efeito de genótipos de milho no desenvolvimento de Spodoptera frugiperda (J.E. Smith). Anais da Sociedade Entomológica do Brasil, v.26, n.2, p.291-298, 1997.

SIMMONDS, M.S.J.; STEVENSON, P.C.; PORTER, E.A. et al. Insect antifeedant activity of three new tetranortriterpenoids from Trichilia pallida. Journal of Natural Products, v.64, p.1117-1120, 2001.

SOUZA, A.P. de; VENDRAMIM, J.D. Atividade ovicida de extratos aquosos de meliáceas sobre a mosca branca Bemisia tabaci (Gennadius) biótipo B em tomateiro. Scientia Agricola, v.57, n.3, p.403-406, 2000b.

SOUZA, A.P. de; VENDRAMIM, J.D. Efeito de extratos aquosos de meliáceas sobre Bemisia tabaci biótipo B em tomateiro. Bragantia, v.59, n.2, p.173179, 2000a. 
SOUZA, A.P. de; VENDRAMIM, J.D. Atividade inseticida de extratos aquosos de meliáceas sobre a mosca-branca Bemisia tabaci (Genn.) biótipo B (Hemiptera: Aleyrodidae). Neotropical Entomology, v.30, n.1, p.133-137, 2001.

THOMAZINI, A.P.B.W.; VENDRAMIM, J.D.; LOPES, M.T.R.L. Extratos aquosos de Trichilia pallida e a traça-do-tomateiro. Scientia Agricola, v.57, n.1, p.13-17, 2000.

TINTO, W.F.; JAGESSAR, P.K.; KETWARU, P. Constituents of Trichilia schomburgkii. Journal of Natural Products, v.54, n.4, p.972-977, 1991.

TORRECILLAS, S. Efeito de extratos aquosos de Trichilia pallida Swartz (Meliaceae) no desenvolvimento de Spodoptera frugiperda (J.E. Smith, 1797) (Lepidoptera: Noctuidae) criada em diferentes genótipos de milho. Piracicaba, 1997. 141p. Dissertação (Mestrado) - Escola Superior de Agricultura "Luiz de Queiroz", Universidade de São Paulo.

TORRECILLAS, S.M.; VENDRAMIM, J.D. Extratos aquosos de ramos de Trichilia pallida e o desenvolvimento de Spodoptera frugiperda em genótipos de milho. Sientia Agricola, v.58, n.1, p.27-31, 2001.

VALICENTE, F.H.; CRUZ, I. Controle biológico da lagarta-do-cartucho, Spodoptera frugiperda, com o baculovírus. Sete Lagoas: Embrapa, 1991. 23p. (EMBRAPA-CNPMS, Circular Técnica, 15).

VENDRAMIM, J.D.; FANCELLI, M. Efeito de genótipos de milho na biologia de Spodoptera frugiperda (J.E. Smith, 1797) (Lepidoptera, Noctuidae). Anais da Sociedade Entomológica do Brasil, v.17, p.141-150, 1988. 
VENDRAMIM, J.D.; SCAMPINI, P.J. Efeito do extrato aquoso de Melia azedarach sobre o desenvolvimento de Spodoptera frugiperda (J.E. Smith) em dois genótipos de milho. Revista de Agricultura, v.72, n.2, p.159-170, 1997.

VILLAR M., C.; AYZLA A., J.L.; RODRÍGUEZ H., C.; LAGUNES T., A. Utilizacion de infusiones y extractos acuosos vegetales en el combate del gusano cogollero del maiz, Spodoptera frugiperda (J.E. Smith) (Lepidoptera: Noctuidae) en San Luis Potosí. Revista de Chapingo, v.15, n.67-68, p.105$107,1990$.

WAQUIL, J.M.; VIANA, P.A.; LORDELLO, A.I.; CRUZ, I.; OLIVEIRA, A.C. Controle da lagarta-do-cartucho em milho com inseticidas químicos e biológicos. Pesquisa Agropecuária Brasileira, v.17, n.2, p.163-166. 1982.

WARTHEN JUNIOR, J.D. Neem (Azadirachta indica A. Juss): organisms affected and reference list update. Proceedings of the Entomological Society of Washington, v.91, n.3, p.367-388, 1989.

WHEELER, D.A.; ISMAN, M.B. Antifeedant and toxic activity of Trichilia americana extract against the larvae of Spodoptera litura. Entomologia Experimentalis et Applicata, v.98, p.9-16, 2001.

WHEELER, D.A.; ISMAN, M.B.; SANCHES-VINDAS, P.E. et al. Screening of Costa Rica Trichilia species for biological activity against the larvae of Spodoptera litura (Lepidoptera: Noctuidae). Biochemical Systematics and Ecology, v.29, p.347-358, 2001. 
WISEMAN, B.R.; DAVIS, F.M; CAMPBELL, J.E. Mechanical infestation device used in fall armyworm plant resistance programs. Florida Entomologist, v. 63, n.4, p.425-432, 1980.

XIE, Y.S.; ISMAN, M.B.; GUNNING, P. et al. Biological activity of extracts of Trichilia species and the limonoid hirtin against lepidopteran larvae. Biochemical Systematics and Ecology, v.2, n.2, p.129-136, 1994. 